\title{
Stress Allostasis in Substance Use Disorder: Promise, Progress, and Emerging Priorities in Clinical Research
}

When citing this paper, please use the following: Fronk GE, Sant'Ana SJ, Kaye JT, Curtin JJ. 2020. Stress Allostasis in Substance Use Disorder: Promise, Progress, and Emerging Priorities in Clinical Research. Annu. Rev. Clin. Psychol. 16: Submitted. DOI: I0.II46/annurev-clinpsy-1024 I9-I250I6

\section{Gaylen E. Fronk', Sarah J. Sant'Ana', Jesse T. Kaye ${ }^{2,3}$, and John J. Curtin'}

\begin{abstract}
Clinicians and researchers alike have long believed that stressors play a pivotal etiologic role in risk, maintenance, and/or relapse of alcohol and other substance use disorders (SUDs). Numerous seminal and contemporary theories on SUD etiology posit that stressors may motivate drug use and that individuals who use drugs chronically may display altered responses to stressors. We use foundational basic stress biology research as a lens through which to evaluate critically the available evidence to support these key stress-SUD theses in humans. Additionally, we examine the field's success to date in targeting stressors and stressor allostasis in treatments for SUDs. We conclude with our recommendations for how best to advance our understanding of the relationship between stressors and drug use, and we discuss clinical implications for treatment development.
\end{abstract}

\section{Keywords}

Stress, addiction, substance use disorders, allostasis, treatment

\footnotetext{
'Department of Psychology, University of Wisconsin, Madison, WI 53706, USA

${ }^{2}$ William S. Middleton Memorial Veterans Hospital, Madison, WI 53705, USA

${ }^{3}$ Center for Tobacco Research and Intervention, University of Wisconsin School of Medicine and Public Health, Madison, WI 537II, USA

\section{Corresponding Author:}

John J. Curtin, Department of Psychology, University of Wisconsin, Madison, WI 53706, USA. Email: jicurtin@wisc.edu
} 


\section{INTRODUCTION}

God grant me the serenity to accept the things I cannot change,

Courage to change the things I can,

and the Wisdom to know the difference.

The prominence of Reinhold Niebuhr's serenity prayer in Alcoholics Anonymous and other 12-step programs reflects their belief about the risks to recovery posed by the stressors and challenges that are an unavoidable part of life. It also acknowledges that successful adaptation requires careful appraisal and subsequent flexible coping matched to each stressor's characteristics and context. This focus on stressors is not limited to 12 -step programs; it permeates the treatment community. Clinicians and patients carefully consider stressors in the context of many interventions for substance use disorders (SUDs).

Given their putative clinical import, it is unsurprising that stressors and maladaptive stress allostasis have figured prominently in classic and contemporary theories on etiology, maintenance, and relapse to SUDs. What is surprising is the too-frequent disconnect of human clinical research on these theories from guiding principles and approaches in basic stress research. The goal of this review is to distill lessons from basic stress research and use them as a lens through which to evaluate progress studying stress-SUD mechanisms in humans. To do this, we begin with a primer on wellestablished concepts, characteristics, and conclusions regarding stressors and stress allostasis. This provides important guideposts to identify lacunae that have escaped the attention of SUD researchers to date. This also provides guardrails to constrain us to relatively well-trodden roads in basic stress research with respect to the research designs, stressors, and stress measures we consider within SUD research.

Next, we highlight the theoretical frameworks that shape current perspectives about stress mechanisms in SUD etiology and drug use. We extract two shared core theses from these theories: Stressors cause drug use, and chronic drug use alters stress allostasis. We briefly summarize relevant preclinical research and follow with a critical evaluation of the available evidence regarding these theses in human clinical research. We then consider our success to date translating this research into stress-focused treatment for SUDs. We conclude by using identified well-supported conclusions, obvious knowledge gaps, and our lens from basic stress research to propose new priorities to advance clinical research and treatment at the intersection of stress and SUDs.

\section{GUIDEPOSTS AND GUARDRAILS FROM BASIC RESEARCH ON STRESS}

\section{Origins of the Stress Concept}

Stress biology research arguably began in earnest early in the twentieth century with the seminal work of Walter Cannon and Hans Selye. In 1915, Cannon coined the expression "fight or flight" 
response to describe an animal's sympathetic nervous system response to a threat (Cannon 1915). He also defined homeostasis as a set of acceptable values for physiologic parameters necessary for survival (Cannon 1932). Following in Cannon's footsteps, Selye $(1936,1975)$ introduced the term stress as we use it today and established that failure to adapt to chronic stress results in disease. Richard Lazarus and others later expanded the biological framing of stress to include psychological as well as physical threats (Burchfield 1979; Lazarus 1966, 1999; Mason 1975). These authors also delineated how appraisal of a threat produces discrete negative emotions (e.g., anxiety, anger, sadness) in addition to autonomic and neuroendocrine stress responses.

\section{Stressors: Definition and Key Characteristics}

Modern theories define stressors as physical or psychological stimuli that disrupt homeostasis within an organism and demand adaptation (McEwen \& Gianaros 2011). Stressors include physical threats as well as current, anticipated, or even imagined psychological threats to "social status, selfesteem, identity, or physical well-being, such as divorce, the death of a loved one, the loss of a job, being arrested, retirement, or being diagnosed with a serious illness" (Cohen et al. 2019, p. 578).

Stressors vary across several dimensions (e.g., predictability, controllability, intensity) (Weiss 1972). Appraisal processes, available coping resources, and context, including social support, are also important (Lazarus 1999, Mason 1975). Stressor duration, developmental timing, and course matter as well. Stressors may be acute and time limited (i.e., discrete, punctate events), chronic intermittent (i.e., related acute events with some expectation of future relief), or chronic and stable with no end in sight (Segerstrom \& Miller 2004).

The experience of and consequences following stressor exposure are typically nonlinear (i.e., inverted-U) as a function of stressor severity for most important cognitive, behavioral, emotional, and health outcomes. Functional impairment is associated with both ends of the severity continuum: Too little arousal is understimulatory, but too much stress is distressing and negatively affects most studied end points (Arnsten 2009, Sapolsky 2015). Optimal stress exposure is associated with arousal, alertness, and engagement, and it is perceived as a challenge rather than a threat (Lazarus 1966, Selye 1975). Characteristics of this inverted-U (e.g., width and peak as a function of severity) display important variability across individuals (Sapolsky 2015).

\section{Stress Allostasis: Definition}

Stress allostasis refers to the set of adaptational processes that are recruited in response to stressors to maintain or return to homeostasis; this definition recognizes that there is no single set point for most parameters but rather continuously changing acceptable ranges (McEwen \& Wingfield 2010). Allostasis can be reactive or proactive and can include both successful (health-promoting) and less successful (health-damaging) behaviors such as diet, physical activity, sleep, smoking, and alcohol consumption (McEwen 2017, McEwen \& Gianaros 2011). Following Sapolsky (2015), we refer to an 
Annual Reviews of Clinical Psychology 16

individual's synthetic experience of active, dynamic, and multisystemic adaptation in the face of stressors as "stress."

\section{Systems and Mediators of Stress Allostasis}

The central nervous system (CNS), autonomic nervous system (ANS), and hypothalamic-pituitaryadrenal (HPA) axis are three important systems that mediate stress allostasis following a stressor. Figure 1 depicts these biological stress systems and details their coordinated actions to regain homeostasis. The CNS (Figure 1a) is a crucial organ in the stress response because it identifies what is threatening (and therefore, stressful) and also coordinates the behavioral and physiological responses (McEwen \& Gianaros 2011). In particular, the extended amygdala, which includes the amygdala and the bed nucleus of the stria terminalis, integrates threat-relevant information via inputs from the prefrontal cortex (PFC), hippocampus, and other brain regions that process information critical for threat appraisal (Fox \& Shackman 2019). It also coordinates behavioral and peripheral components of stress allostasis via projections to prefrontal, hypothalamic, subcortical effector, and brain stem regions. Distinct circuits within the extended amygdala may be selectively engaged depending on the nature of the stressor, with corticotropin-releasing hormone (CRH) signaling in the central extended amygdala particularly important during uncertainty (Davis et al. 2010; but see Fox \& Shackman 2019).

The HPA axis (Figure 1b) is a key neuroendocrine system that works in tandem with the ANS to mediate peripheral stress allostasis. The HPA axis consists of the hypothalamus, pituitary gland, and adrenal glands. Stressor activation of the HPA axis initiates release of glucocorticoids (e.g., cortisol) that affect many tissues in the body and CNS. The ANS (Figure 1c) comprises two major divisions, the sympathetic and parasympathetic nervous systems, which have opposing functions in many instances. The sympathetic nervous system mediates the fight-or-flight response, whereas the parasympathetic nervous system regulates feed-and-breed or rest-and-digest responses. These quicker and more organ-specific actions of the ANS complement the slower and longer-lasting hormonal responses of the HPA axis.

These three stress systems do not operate in isolation; rather, they display both short-term and long-term positive and negative feedback loops. For example, the CNS exerts top-down control over the ANS via the brain stem, thalamus, hypothalamus, amygdala, cingulate cortex, and PFC (Lane et al. 2009) but also receives feedback from target organs via afferent sensory fibers. Similarly, connections in the CNS among regions including the extended amygdala, hippocampus, PFC, and hypothalamus can facilitate or inhibit activation of the HPA axis. Glucocorticoids from the adrenal glands exert short-term negative feedback on the HPA axis, inhibiting further release of CRH from the hypothalamus. However, glucocorticoids also produce long-lasting changes in the CNS including atrophy in the hippocampus and PFC but also hypertrophy in the extended amygdala (Chattarji et al. 2015). 
A.

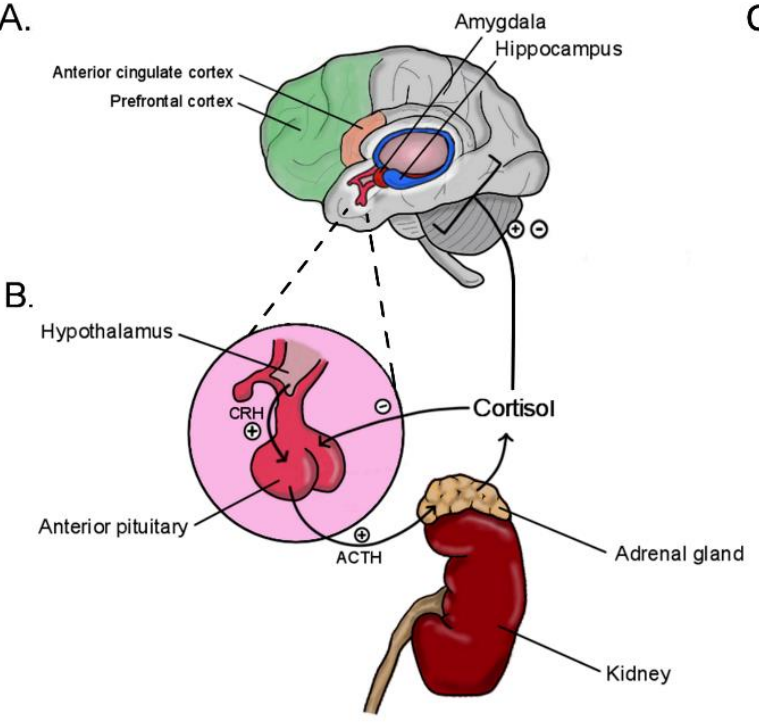

C.

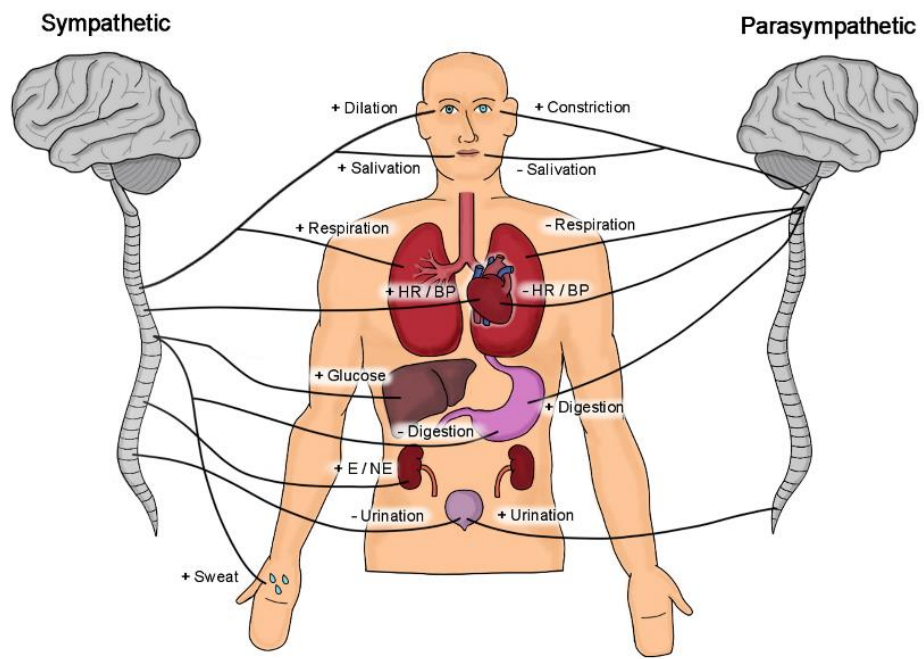

\section{Figure 1}

Biological stress systems. (A) The central nervous system (CNS) plays a critical role in stressor appraisal and also controls the behavioral, emotional, autonomic nervous system (ANS), and hypothalamic-pituitary-adrenal (HPA) axis responses to stressors (McEwen \& Gianaros 2011). Within the CNS, the extended amygdala is becoming an increasing focus of study for researchers interested in the intersection of stress and psychopathology including substance use disorders (SUDs) (Fox \& Shackman 2019). The extended amygdala is primarily composed of the central and medial nuclei of the amygdala and the bed nucleus of the stria terminalis (not depicted). The extended amygdala integrates information relevant for stressor appraisal via its inputs from the prefrontal cortex and other brain regions that process sensory, contextual, regulatory, and evaluative information. It also coordinates emotional, behavioral, autonomic, and neuroendocrine allostatic responses to stressors via its established projections to prefrontal, hypothalamic, subcortical effector, and brain stem regions. The hypothalamus connects the CNS to the HPA axis stress response and also has direct influence over the ANS. The hypothalamus receives predominantly inhibitory input from the hippocampus, which appears to influence both the onset and shutoff of HPA axis activity (McEwen \& Gianaros 2011), and excitatory input from the extended amygdala. (B) The HPA axis is a major neuroendocrine system that works in tandem with the ANS to mediate peripheral stress allostasis. The HPA axis consists of the paraventricular nucleus (PVN) of the hypothalamus, the pituitary gland, and the adrenal glands (on the top of the kidneys). Stressors stimulate PVN neurons to synthesize and release corticotropin-releasing hormone (CRH) into portal blood vessels that connect the PVN to the pituitary gland. Within approximately $15 \mathrm{~s}$, CRH binds to receptors on pituitary corticotropes, and this process stimulates adrenocorticotropic hormone (ACTH) release into systemic circulation. Within a few minutes, ACTH induces glucocorticoid (primarily cortisol in humans) release from the cortex of the adrenal glands. These glucocorticoids combine with epinephrine (E) and norepinephrine (NE) from the ANS to mediate the body's response to stressors. These glucocorticoids provide negative feedback to CRH neurons in the hypothalamus to regulate their own release. Glucocorticoids also provide divergent feedback to extrahypothalamic sites in the CNS including the hippocampus, amygdala, and prefrontal cortex to regulate current and future CNS stress allostasis (Chattarji et al. 2015). (C) The ANS is the largely involuntary branch of the nervous system that projects to organs, glands, and nonskeletal muscle. It comprises the sympathetic and parasympathetic nervous systems, which have complementary functions during stress allostasis. The sympathetic division (left) consists of cell bodies that emerge from the thoracic and lumbar regions of the spinal cord. It mediates peripheral arousal, activation, and mobilization to respond adaptively to stressors through a cascade of effects including increased heart rate (HR), blood pressure (BP), respiration, sweating, and others depicted in panel c (i.e., fight-or-flight responses). In contrast, the parasympathetic division (right) consists of cell bodies that emerge from the cervical and sacral regions. Stressors suppress parasympathetic functions like growth, energy storage, and digestion (i.e., feed-and-breed or rest-and-digest responses). Original figure created by Peter Shireman. 
Annual Reviews of Clinical Psychology 16

\section{THEORIES AND THESES OF STRESS ALLOSTASIS IN SUBSTANCE USE DISORDERS}

We now provide an overview of stress-relevant theoretical frameworks and models on SUD etiology. We combine the preceding primer on basic stress research with these SUD theories to propose directives to guide our review of stress mechanisms in SUDs.

\section{Guiding Theoretical Frameworks and Specific Models}

The following theoretical frameworks comprise seminal and contemporary perspectives on the relationship between stress and SUD etiology. These frameworks include negative reinforcement models, stress neuroadaptation models, and stress-impaired self-control models.

Negative reinforcement models. Negative reinforcement models that invoke stress mechanisms have contributed to our understanding of the etiology and maintenance of SUDs. The stress response dampening model proposes that alcohol and other drug use is reinforcing because it acutely dampens aversive components of the stress response (e.g., affective distress), thereby increasing drug use over time during stress (Sher 1987). Baker and colleagues (2004) posit that, over repeated drug use episodes, individuals learn that discontinuing drug use leads to escalating withdrawal with associated affective distress that can be ameliorated by resuming drug intake. Subsequently, affective distress from withdrawal or stressors motivates further drug use or relapse following cessation. Khantzian's (1997) self-medication model asserts that individuals use drugs to cope with affective distress associated with psychiatric illness (e.g., posttraumatic stress disorder [PTSD]) generally or acutely during stressors. More recently, Gorka and colleagues have suggested that stable, exaggerated reactivity to unpredictable (versus predictable) stressors specifically provides a target for negative reinforcement, at least in alcohol use disorder (AUD) (Gorka et al. 2019, Gorka \& Shankman 2017).

Stress neuroadaptation models. Koob \& Le Moal (2008) have derived a stress neuroadaptation model based on classic opponent process principles whereby countervailing CNS stress systems are recruited to oppose drug use-induced pleasure, positive affect, and reward-related activity and restore affective homeostasis. Repeated recruitment of these CNS stress systems to maintain affective homeostasis in the face of chronic drug use causes allostatic neuroadaptations that result in stronger, more persistent activation of these CNS stress systems during stressor exposure. Elaborating on this theoretical foundation, Kaye et al. (2017) synthesized preclinical and clinical research using startle potentiation to implicate unpredictable stressors as particularly potent instigators of this CNS stress allostasis. Regardless, these theorists agree that additional drug use following stressor exposure is then motivated via negative reinforcement like other negative reinforcement models.

Stress-impaired self-control models. Stressors may also affect drug use indirectly by impairing self-control processes that regulate appetitive behaviors more generally. For example, both acute and chronic stress exposure have been demonstrated to disrupt PFC network connections and 
markedly impair PFC functions that are critical for self-control (Arnsten 2009). Arnsten (2009) has suggested that uncontrollable stressors may produce particularly powerful deficits. Regardless, these stress-instigated deficits in self-control may undermine efforts to resist drug use that is motivated by these same stressors (e.g., via negative reinforcement) or other instigators for drug use (e.g., drug cues, drug priming doses) (Curtin et al. 2006).

\section{Core Shared Theses}

There is substantial overlap among these theoretical frameworks and specific models on the role of stressors in SUD etiology. Most models share two core theses. For each, we first briefly summarize evidence from animal models for these theses, as this preclinical literature was instrumental in developing at least some models or their precursors (e.g., Kaye et al. 2017, Koob \& Le Moal 2008, Sher 1987). We follow these summaries with critical evaluations of the evidence regarding these two theses in humans in subsequent sections.

Core thesis 1: Stressors cause drug use. Across models, stressors are expected to motivate drug use in continuing users and prompt lapse or relapse among those pursuing abstinence. Preclinical rodent models provide robust evidence for stressor-induced reinstatement of previously extinguished drug seeking (for review, see Mantsch et al. 2016). Specifically, there is strong evidence that acute unpredictable foot-shock stressors robustly reinstate self-administration and drug seeking behavior across all classes of addictive drugs. However, the evidence is mixed with respect to the generality of stress-induced reinstatement across other various external stressors (e.g., food deprivation, restraint) and putative pharmacological stressors (e.g., yohimbine, CRH administration). That said, the most widely used reinstatement stressors in rodent models are acute, unpredictable, and uncontrollable (Kaye et al. 2017, Mantsch et al. 2016).

Core thesis 2: Chronic drug use alters stress allostasis. A core tenet of the stress neuroadaptation models is that chronic drug use produces persistent changes in stress allostasis to maintain homeostasis in the face of frequent drug use. Unfortunately, these same allostatic changes promote further drug use, perpetuating a cycle of continued allostatic adaptations and escalating drug use. Many negative reinforcement models also propose or at least allow for either premorbid/stable or drug-induced maladaptive stress allostasis among individuals with SUDs. Given this, maladaptive stress allostasis should emerge when comparing individuals with SUDs with healthy controls.

Preclinical research has observed maladaptive stress allostasis following chronic drug use. Animal models have demonstrated a behavioral phenotype of increased anxiety-like behavior in rodents following chronic drug exposure, particularly during periods of drug deprivation (Koob 2015, Smith \& Aston-Jones 2008). Of note, this behavioral phenotype has been established in tasks that use unpredictable stressors as part of the assay themselves (e.g., elevated-plus maze; foot shock instigating defensive burying). This suggests that the heightened anxiety-like behavior is stress relevant ( Kaye et al. 2017, Smith \& Aston-Jones 2008). Chronic drug use also leads to countervailing 
Annual Reviews of Clinical Psychology 16

effects in the HPA axis versus the CNS. Specifically, whereas the HPA axis stressor response becomes blunted following chronic drug use, CRH neurotransmission in the extended amygdala becomes sensitized (

\section{Directives for Studying Stress Mechanisms in Substance Use Disorders}

Synthesis of basic stress research and these guiding theories yielded the following directives to organize our evaluation of human clinical research on stress mechanisms in SUDs. First, we remain cognizant of stressor characteristics and context (e.g., intensity, predictability) as well as individual differences in stressor appraisal, coping, and stress allostasis. These elements may act as key moderators or boundary conditions. Second, we avoid aggregating across biological stress systems into a homogeneous and simplistic stress-reactivity construct given the established positive and negative feedback within and between stress systems. This allows for the possibility of different patterns of stress allostasis across systems among individuals with SUDs (e.g., blunted HPA axis and sensitized CNS response). Third, we limit our focus to well-established measures of CNS, ANS, HPA axis, and subjective emotional response to stressors.

We also focus on research that manipulates or measures explicit physical and psychological stressors, excluding studies of mood, tonic emotion, or baseline activity absent a clearly identified eliciting stressor. Animal models have clarified that stress mechanisms such as CRH-1 and norepinephrine (NE) mechanisms support dynamic, active response to an acute stressor rather than tonic, persistent mood states (Koob \& Zorrilla 2010). The most common psychological stressors involve personalized or standardized stress imagery (e.g., Sinha 2009), variants of evaluative public speaking (e.g., Trier social stress task), negative peer evaluation or failure feedback, negative mood induction with unpleasant pictures or music, threat of electric shock [e.g., NPU task (Schmitz \& Grillon 2012)], and difficult speeded mental tasks (e.g., modified paced auditory serial addition task). Physical stressors (e.g., cold pressor test, aversive noise exposure) or combined physical and psychological stressors are also used (e.g., Maastricht acute stress test). Manipulation checks to confirm that stressors elicit robust response on one or more stress measures are commonly used, and we ignore studies that observed no impact on those stress measures.

Finally, recent conversations about sample size and power have made clear that conclusions from small-N research suffer from a host of problems that reduce robustness and replicability (e.g., increased type II errors, low positive predictive value, high vibration of effects) (Button et al. 2013, Tackett et al. 2019). As such, we prioritize evidence from studies with sample sizes and designs likely to yield at least adequate power to detect medium effect sizes $(\sim 70 \%$ or greater; coarsely approximated at $\geq 100$ and $\geq 25$ subjects for between- and within-subject designs, respectively). Unless we explicitly state otherwise, we limit our discussion to findings from these studies with adequate sample sizes and instead describe small-N studies primarily in Supplemental Tables 1-4 for completeness. Following these directives, we turn now to critical reviews of the evidence for these two core 
shared theses, followed by a consideration of progress to date in targeting stress mechanisms in treatment of SUDs.

\section{STRESS-INDUCED CRAVING, DRUG USE, OR RELAPSE IN SUBSTANCE USE DISORDERS}

Stress-induced craving, drug use, and/or relapse is expected across negative reinforcement, stress neuroadaptation, and stress-impaired self-control models. To evaluate this first core shared thesis in humans, we carefully considered research examining either stress-induced craving, drug use, or relapse among individuals with SUDs (or daily/near-daily users of tobacco and cannabis). We considered both laboratory (see Supplemental Table 1) and in situ (see Supplemental Table 2) studies because they offer complementary strengths and weaknesses with respect to causal claims, ecological validity of the stressors and drug use outcome measures, and the temporal ordering and lags between stressors and outcomes.

\section{Laboratory Research}

Laboratory research offers precise manipulation of stressors, clear temporal ordering of stressor versus craving/use, and the tightly controlled environments necessary to demonstrate cause definitively. Of course, these benefits also come with a cost to ecological validity both with respect to the stressors used and the measurement of drug use.

Craving. There is generally strong support for stress-induced craving across drugs in individuals with SUDs from both meta-analyses and individual studies. For example, stress-induced craving among tobacco smokers has been clearly established in a recent meta-analysis of 26 laboratory studies, with the magnitude of craving increasing with increased self-reported negative affect elicited by the stressor ( use disorder and AUD (Coffey et al. 2002, 2006, 2010; Cooney et al. 1997; Fox et al. 2008; Ray 2011; Sinha et al. 2003, 2009), though there have been several null findings for AUD as well (Jansma et al. 2000, Mason et al. 2008, Pratt \& Davidson 2009). Constantinou et al. (2010) did not observe stressinduced craving for opioid use disorder. Across drugs, stress-induced craving has generally been confirmed both for individuals seeking and not seeking treatment.

Drug use. Convincing evidence of stress-induced drug use has yet to be provided for individuals with SUDs who are not seeking treatment. A meta-analysis of 12 studies concluded that laboratory stressors reliably decreased latency to smoke and increased number of puffs taken by tobacco smokers ( ther of those already small stress-induced use effects were robust to subsequent corrections for publication bias. Pratt \& Davidson (2009) did not observe stress-induced drinking, and small- $N$ studies for AUD have yielded inconsistent findings. We are not aware of studies of stress-induced use for other drugs among individuals not seeking treatment. Because of ethical constraints, no 
Annual Reviews of Clinical Psychology 16

laboratory studies examined stress-induced relapse among abstinent or treatment-seeking participants with any SUDs.

\section{In situ Research}

Historically, most in situ studies have measured only self-reported negative affect. This prohibits definitive conclusions about stressor-elicited distress because it may instead reflect variation associated with ongoing, stimulus-independent mood, trait affectivity, psychiatric symptoms, and other sources. Only recently have in situ studies begun to measure stressful events explicitly. This small set of studies varies substantially on methods and analytic strategies: There are differences in how reports are signaled (e.g., random, event-triggered, end of day), the reporting window (e.g., craving right now, maximum craving since last report, number of stressful events that day), and the measurement approach (presence/absence or count of stressors/drug use instances in a window, intensity of stressor, quantity of drug used). Analyses can test for concurrent or lagged prospective relationships between stressors and their consequences, and prospective analyses can vary in lag duration (next report, same evening, next day). These varied methods and analyses likely differ with respect to their power to detect stress-induced effects, but at this point there are too few studies to reach any clear conclusions about preferred approaches.

Craving. In situ studies have consistently observed a positive association between concurrent stressful events and craving (Moran et al. 2018, Neupert et al. 2017, Preston et al. 2017, Serre et al. 2018, Volz et al. 2014). Of course, because concurrent analyses cannot establish temporal ordering of stressful events and craving, it remains possible that the experience of craving prompts individuals to report a stressful event (e.g., concern about lapse/relapse). Few studies to date have examined prospective associations between stressful events and the report of craving, and the existing studies have shown mixed results (Neupert et al. 2017, Preston et al. 2018a, Serre et al. 2018).

Drug use. Similar to craving, a concurrent positive association has been observed between stressful events and drug use, but this association shares the same concerns about temporal ordering (Neupert et al. 2017, Preston et al. 2018b). Consistent evidence for a prospective relationship has not yet been provided (Armeli et al. 2007, Cronk \& Piasecki 2010, Furnari et al. 2015, Neupert et al. 2017, Shiffman \& Waters 2004). Despite the inconsistency thus far, this nascent field holds great promise for examining stress-induced drug use, a priority to which we return at the end of this review.

\section{MALADAPTIVE STRESS ALLOSTASIS IN SUBSTANCE USE DISORDERS}

Maladaptive stress allostasis among individuals with SUDs is expected by stress neuroadaptation and many negative reinforcement models. To evaluate this second core shared thesis in humans, we carefully considered research examining stress allostasis in central and peripheral stress systems among individuals with SUDs (versus healthy controls; see Supplemental Table 3) and during periods of drug deprivation/cessation (versus continuing users; see Supplemental Table 4) following 
previously outlined directives. When available, we also report contrasts involving former drug users in protracted abstinence.

\section{Peripheral Stress Allostasis}

Convincing evidence indicates that current smokers display blunted HPA axis and sympathetic nervous system response to stressors relative to nonsmokers (al'Absi et al. 2013, Evans et al. 2012, Ginty et al. 2014, Nakajima \& Al'Absi 2014, Phillips et al. 2009, Sheffield et al. 1997; but see Ward et al. 1994). These studies considered a diverse array of physical and psychological stressors and measures of stress allostasis in the HPA axis and sympathetic nervous system. This blunted response was generally observed across all or almost all outcome measures and was robust to including covariates to control nonessential group differences.

Unfortunately, we are not aware of similar studies examining HPA axis and sympathetic nervous system allostasis among individuals with SUDs for drugs other than tobacco. Small-N studies (see Supplemental Table 3) have generally documented blunted salivary, urinary, or plasma cortisol and plasma adrenocorticotropic hormone among recently abstinent individuals with AUD, but there is insufficient empirical evidence to reach any conclusions regarding ANS allostasis for alcohol or HPA axis or ANS allostasis for other drugs because of the sparsity and quality of available studies.

Few studies have examined the impact of acute deprivation or early cessation of use on peripheral stress allostasis, and this work has been limited to tobacco smokers. There has been some indication of further blunting of peripheral stress allostasis by deprivation/cessation (Vanderkaay \& Patterson 2006) but also null effects (Ward et al. 1994). There is also some evidence of normalization of peripheral stress allostasis following protracted abstinence from drug use. For example, two tobacco studies concluded that ex-smokers' peripheral stress allostasis was comparable to nonsmokers' with respect to measures of HPA axis (Ginty et al. 2014) and sympathetic nervous system response (Ginty et al. 2014, Phillips et al. 2009).

\section{Central Nervous System Stress Allostasis}

Numerous studies have investigated CNS stress allostasis using startle response modulation or potentiation (for review of neural mechanisms, see Davis et al. 2010). This research has typically used unpleasant pictures or threat of electric shock as stressors. Of particular interest, most research involving threat of electric shock has used both predictable and unpredictable shocks to examine the effects of stressor predictability as well as overall CNS stress response. In fact, stressor predictability does appear to matter with respect to SUD effects. Individuals with AUD, daily tobacco smokers, and near-daily cannabis users generally display increased startle response to unpredictable but not predictable stressors relative to healthy controls (Grillon et al. 2007, Gorka \& Shankman 2017, Hefner et al. 2018, Moberg et al. 2017, Piper \& Curtin 2006; but see Bradford et al. 2015).

Although substantial functional magnetic resonance imaging (fMRI) research has examined drug

cue reactivity among individuals with SUDs, only a few small-N studies have explored CNS stress 
allostasis. Unsurprisingly, these studies have not yielded consistent conclusions. Different studies have observed hypoactivation and hyperactivation in the same regions in individuals with SUDs, and others have observed no differences between individuals with SUDs and healthy controls (see Supplemental Table 3). Clearly, it is premature to reach conclusions about potential differential CNS stress allostasis from this emerging fMRI literature.

Acute tobacco deprivation has not affected startle response modulation during unpleasant pictures (Cinciripini et al. 2006) or threat of predictable or unpredictable shock (Bradford et al. 2015, Grillon et al. 2007; but see Hogle et al. 2010). Small-N studies consistently confirm these null effects for tobacco deprivation (Supplemental Table 4). Hefner et al. (2018) also observed no effect of acute deprivation on startle potentiation to unpredictable shock among near-daily cannabis users. We are not aware of similar research examining acute deprivation for other drugs, but this research with tobacco and cannabis suggests that deprivation does not alter CNS stress allostasis, at least as assessed by the startle response.

We are not aware of research explicitly examining CNS stress allostasis among users in protracted abstinence. However, Gorka and colleagues (2019) have demonstrated increased startle potentiation to unpredictable shock among participants with both current and past AUD (up to 2 years of sustained remission) with no differences between these two subgroups.

\section{Subjective Distress}

Like research on peripheral allostasis, the only studies to systematically examine SUD group differences in subjective distress involve tobacco. None of these studies observed differences in subjective distress in response to stressors between current tobacco smokers and nonsmokers (al'Absi et al. 2013, Bradford et al. 2015, Evans et al. 2012, Nakajima \& Al'Absi 2014). Numerous small-N studies for tobacco and alcohol generally confirm these null effects. Inconsistent and/or insufficient findings for cocaine, cannabis, and opioids prevent clear conclusions for these drugs (see Supplemental Table 3).

Bradford et al. (2015) observed no effect of $24 \mathrm{~h}$ of tobacco deprivation on subjective distress in smokers versus nondeprived tobacco smokers. Small-N laboratory studies have generally reached the same conclusion (see Supplemental Table 4). However, McCarthy et al. (2006) observed that the relationship between stressful events and negative affect was stronger among smokers in the 3 weeks after quitting smoking relative to their prequit baseline; this finding suggests that smoking cessation rather than simply acute laboratory deprivation may increase stressor-instigated distress.

\section{TREATMENTS THAT TARGET STRESS ALLOSTASIS IN SUBSTANCE USE DISORDERS}

We now review treatments that may affect stress allostasis and associated stress-induced relapse among individuals with SUDs. We focus on treatments that may improve SUD clinical outcomes 
specifically via stress mechanisms to evaluate our success to date in targeting stress allostasis in SUDs. Furthermore, "manipulations" of stress allostasis via treatment can provide further evidence regarding the hypothesized relationship between stressors and drug use proposed by our guiding theoretical models.

\section{Stress-Relevant Pharmacologic Treatments}

We limit the review of pharmacological interventions to those that reduce stress-induced reinstatement of drug seeking in rodents.

Preclinical evidence. Animal models have clearly established that CRH-1 receptors mediate CNS, neuroendocrine, ANS, and behavioral responses to stressors in rodents (Koob \& Zorrilla 2010). Furthermore, CRH-1 receptor antagonists potently reduce stress-induced reinstatement to alcohol, tobacco, cocaine, opioids, and methamphetamine (Mantsch et al. 2016). These preclinical findings generated considerable excitement for CRH-1 antagonists to target stress-induced relapse in SUDs (Koob \& Zorrilla 2010).

Although somewhat less consistent than studies on $\mathrm{CRH}-1$ receptors, animal models have also generally established that medications that reduce NE neurotransmission via ? 1 antagonists or ? 2 agonists reduce stress-induced reinstatement to alcohol, tobacco, cocaine, and opioids (Mantsch et al. 2016). These preclinical findings have suggested that the NE system is another natural pharmacologic target to reduce stress-induced relapse in SUDs (Kaye et al. 2017, Verplaetse et al. 2015).

Corticotropin-releasing hormone 1 antagonists in humans. Surprisingly, clinical translation of CRH-1 antagonists to humans with AUD has not been successful (Greenwald 2018, Shaham \& de Wit 2016). Two phase II trials (Kwako et al. 2015, Schwandt et al. 2016) failed to demonstrate efficacy for two different brain-penetrant CRH-1 antagonists (pexacerfont, verucerfont) on subjective craving and distress, fMRI amygdala activation, and neuroendocrine response during psychological stressors. These failures occurred despite generally rigorous methods (e.g., both trials recruited samples enriched for anxiety to increase sensitivity) and manipulation checks to confirm that the trials provided adequate test beds to evaluate the clinical efficacy of CRH-1 antagonists [e.g., demonstration of CNS exposure (Kwako et al. 2015), demonstration of HPA axis inhibition (Schwandt et al. 2016), documentation of stress-elicited craving and distress].

Both trials recruited small final sample sizes $(\mathrm{N}=39-54)$ that were only adequately powered to detect large effects and only evaluated laboratory surrogate end points rather than clinical outcomes. However, they join previous failures of CRH-1 antagonists in larger phase III trials for depression, generalized anxiety disorder, and PTSD (Binneman et al. 2008, Coric et al. 2010, Dunlop et al. 2017). In aggregate, these clinical trials represent a striking failure for robust evidence from animal models on the role of central $\mathrm{CRH}$ in mood- and stress-relevant processes to translate to humans. 
Norepinephrine $\alpha 1$ antagonists and $\alpha 2$ agonists in humans. Several medications that reduce NE neurotransmission (by blocking postsynaptic $\alpha 1$ or $\beta$ receptors or by activating presynaptic $\alpha 2$ autoreceptors) have been available for decades, primarily for hypertension and related cardiovascular issues. To date, several phase II trials have demonstrated significant effects for various $\alpha 2$ agonists on stress-relevant surrogate end points or short-term clinical outcomes in patients with different SUDs (e.g., cocaine, tobacco, opioids) (Fox et al. 2012b, Jobes et al. 2011, McKee et al. 2015, Sinha et al. 2007). However, these significant effects were observed for some but not other primary outcomes. Furthermore, sample sizes ranged from as low as $\mathrm{N}=10$ to $\mathrm{N}=59$. As such, we believe it is premature to reach clear conclusions regarding pharmacological manipulations of NE $\alpha 2$ receptors for stress-induced relapse in humans.

With respect to NE $\alpha 1$ antagonists, three small phase II trials $(\mathrm{N}=17-35)$ provided preliminary support for positive impacts on stress-relevant surrogate end points and short-term clinical outcomes for prazosin in AUD (Fox et al. 2012a, Simpson et al. 2009) and for doxazosin in tobacco smokers (Verplaetse et al. 2017). However, a fourth small trial $(\mathrm{N}=41)$ observed no effect of doxazosin on its primary clinical outcomes in patients with AUD (Kenna et al. 2016). More importantly, two more recent studies of prazosin that used somewhat larger sample sizes ( $=92-96)$ observed no effects on similar primary clinical outcomes in patients with AUD (Petrakis et al. 2016, Simpson et al. 2018). These latter null findings somewhat temper optimism for this class of medications to treat stress-induced relapse in humans (Kaye et al. 2019).

Gabapentin in humans. Gabapentin is a widely prescribed gamma-aminobutyric acid B (GABAB) receptor agonist originally marketed as an anticonvulsant and currently prescribed off label for SUDs (Peckham et al. 2018). Gabapentin may stabilize the CNS stress system by normalizing stressor-induced GABA activation in the amygdala (Mason et al. 2018; see also Roberto et al. 2008). It has also been shown to improve potentially stress-relevant negative affect in clinical samples (Mason et al. 2018). To our knowledge, gabapentin has not been evaluated in the canonical stress-induced reinstatement model in rodents. However, pregabalin, a close analog of gabapentin, reduces yohimbine-induced reinstatement of alcohol (Stopponi et al. 2012) and cocaine (de Guglielmo et al. 2013) in rodents.

Gabapentin has produced mixed effects on clinical outcomes for AUD. However, a recent metaanalysis of seven randomized controlled trials (RCTs) concluded that gabapentin reduced percentage of heavy drinking days but none of the other five clinical outcomes considered (Kranzler et al. 2019). With respect to other SUDs, one small-N RCT demonstrated preliminary efficacy of gabapentin for cannabis use (Mason et al. 2012). Gabapentin was not superior to placebo as an adjunct treatment with methadone for opioid use disorder in an RCT (Kheirabadi et al. 2008) or open-label follow-up (Salehi et al. 2011). Gabapentin also showed initial promise for cocaine use in open-label trials (Myrick et al. 2001, Raby \& Coomaraswamy 2004) but not in follow-up RCTs (Bisaga et al. 
2006, González et al. 2007, Hart et al. 2007). To our knowledge, gabapentin's effect on stress-relevant surrogate end points has not been studied.

\section{Stress-Relevant Psychosocial Treatments}

We focus on two psychosocial treatments with face-valid components that target stress mechanisms.

Cognitive behavioral therapy. SUD-tailored cognitive behavioral therapy (CBT) helps patients modify thoughts and behaviors surrounding their drug use and improve functioning in other drug use-related aspects of their lives (e.g., Carroll 2000). Patients learn to identify high-risk situations including periods of stress and/or craving, strengthen coping skills, improve mood and emotion regulation, and enhance social support. Meta-analytic reviews of RCTs have clearly demonstrated that CBT is moderately effective at reducing drug use for various SUDs including alcohol, cannabis, cocaine, tobacco, opioids, and polysubstance use disorders (Dutra et al. 2008, Magill \& Ray 2009).

CBT includes stress-focused training to increase relaxation, stress management, emotion regulation, and distress tolerance. Furthermore, there is a general focus on developing coping skills for high-risk situations. For example, patients learn cognitive reappraisal to reduce negative emotional response to stressors. CBT-based exposure to interceptive cues associated with stress arousal may also help patients better cope and improve drug use outcomes (Zvolensky et al. 2008). Enhanced stressor awareness may also make stressors more predictable and/or controllable, improving coping and further diminishing their impact. Despite these face-valid components, convincing evidence that improved coping with stressors or other stress-relevant processes represent primary mechanisms of action for CBT has yet to be provided (Kiluk \& Carroll 2013, Magill et al. 2015).

Mindfulness meditation-based interventions. Mindfulness-based relapse prevention (Witkiewitz et al. 2014) and related mindfulness meditation-based interventions (MMBIs) for SUDs (e.g., Brewer et al. 2011) target relapse due to craving, stressors, and other instigators. MMBIs for SUDs draw heavily from earlier MMBI approaches targeting stress reduction and relapse to depression (Kabat-Zinn 2005, Segal et al. 2012) and from cognitive behavioral relapse prevention skills (e.g., identifying high-risk situations; coping skills training). MMBIs emphasize intentional awareness and acceptance of all experiences, even those that are distressing, and seek to improve self-regulation and decrease automatic, maladaptive coping responses (e.g., using drugs). MMBIs demonstrate consistent, moderate effectiveness on clinical outcomes for SUDs as evidenced in several recent large RCTs, meta-analyses, and reviews (Bowen et al. 2014, Goldberg et al. 2018, Li et al. 2017, Wielgosz et al. 2019, Witkiewitz et al. 2013).

Preliminary theoretical and empirical evidence suggests that MMBIs may produce these positive clinical outcomes in part by affecting stress allostasis. Wielgosz et al. (2019) suggested that MMBIs may improve response to stressors by altering emotional awareness, emotional reactivity, and/or cognitive reappraisal. They also noted that mindfulness practice may be associated with changes in 
key CNS allostasis structures, improved stressor detection and appraisal, and extinction of emotional reactions to stressors. Specific to SUDs, preliminary evidence suggests that MMBIs may improve stress allostasis on some measures (salivary cortisol, fMRI of CNS stress circuits) but not selfreported distress (Kober et al. 2017, Tang et al. 2016). In addition, Tapper (2018) identified consistent evidence for executive control (working memory load) and top-down extinction processes mediating MMBI effects on cravings for food, cigarettes, and alcohol. However, these conclusions emerged from a small evidence base and often in samples without formal SUD diagnosis. In sum, although MMBIs clearly yield positive clinical benefits for SUDs, further research is needed to delineate stress mechanisms explicitly.

\section{SUMMARY, SYNTHESIS, AND NEW PRIORITIES}

\section{State of the Evidence}

Overall, we believe that the accumulated evidence for stress-induced drug use, craving, and maladaptive stress allostasis in SUDs from human clinical research to date is simultaneously promising but also modest. We offer several confident and some additional, more tentative conclusions with respect to the two shared core theses we have evaluated and the efficacy of available treatments that may affect these stress mechanisms in SUDs.

Stressors cause drug craving in individuals with SUDs. This is relatively clear from laboratory manipulations of stressors but is also supported by concurrent (and some prospective) analyses of stressor-craving relationships from in situ studies. Laboratory stressor manipulations do not consistently increase drug use; however, this research is methodologically limited. Much of the older research is severely underpowered, and there is some concern about the ecological validity of drug use measures obtained in the laboratory. Ethical concerns prevent the study of drug lapses/relapses in the lab as well. Although newer in situ methods can address these limitations, this research has only begun to measure stressful events explicitly and to conduct prospective, appropriately lagged measurement and analyses of stressor-drug use relationships.

Individuals with SUDs display blunted peripheral allostasis in response to punctate stressors relative to healthy controls. This conclusion is robustly supported for ANS allostasis measures such as heart rate and blood pressure but also appears true for measures of HPA axis activation. Conversely, there is some evidence of relatively exaggerated CNS stress allostasis among individuals with SUDs. This exaggerated response may be selective to unpredictable stressors, though evidence is currently limited to startle potentiation in response to predictable versus unpredictable threat of shock. Perhaps surprisingly, there is not consistent support for differential distress in response to stressors for SUDs versus healthy controls. Acute tobacco deprivation does not consistently change allostasis in response to punctate stressors for any stress measures. Acute deprivation from other drugs has 
not been adequately studied. There is insufficient research to reach conclusions about normalization of stress allostasis following protracted drug abstinence.

The preclinical evidence from animal models for the development of CRH-1 antagonists to reduce stress-induced relapse was arguably the strongest of any potential medication to treat stress mechanisms in SUDs (Koob \& Zorrilla 2010). Despite this excitement for CRH-1 antagonists generated from animal models, clinical translation to humans did not succeed (Shaham \& de Wit 2016). Research from animal models suggested that the NE system was another natural pharmacologic target to reduce stress-induced relapse in humans (Kaye et al. 2017, Verplaetse et al. 2015). However, the null findings from two recent clinical trials of prazosin (Petrakis et al. 2016, Simpson et al. 2018) have somewhat tempered optimism for this class of medications to treat stress-induced relapse in humans. Prazosin also may not reduce CNS allostasis in response to either unpredictable or predictable shock as might have been expected from animal models (Kaye et al. 2019). These failures serve as important cautionary reminders that although we can and should be guided by animal models, those models are not sufficient predictors of clinical outcomes (de Wit et al. 2018, Heilig et al. 2016). Confirmatory research in humans, as we have reviewed in this paper, is essential to support mature clinical theories and screen/evaluate interventions.

Convincing evidence has not yet emerged that targeting maladaptive stress allostasis with psychosocial interventions improves clinical outcomes in SUDs. SUD-tailored CBT and MMBIs do improve clinical outcomes. They also include components that have the potential to target stress allostasis. However, rigorous studies have not yet formally demonstrated that stress mechanisms mediate their treatment outcomes.

Our relatively modest conclusions about the current state of the evidence regarding stress-SUD mechanisms stand in somewhat stark contrast to many previous reviews. Often, assertions about stress-SUD relationships cite evidence from animal models and/or blend findings from animals, humans, and other reviews without sufficient transparency. We place high value on animal models of SUDs (Kaye et al. 2017), but the stress-SUD field is now mature enough to require us to strive for clear conclusions supported by human clinical research. The empirical evidence for our assertions must also be explicit and transparent, or we run the risk of circular citation of reviews.

Recent observations about problems with the robustness and replicability of many areas of psychological science including clinical psychology also require circumspection in our conclusions (Tackett et al. 2019). Much of the stress-SUD literature is small-N with associated problems with power, positive predictive value, and vibration of effects (Button et al. 2013). The inconsistent findings across small-N studies in our supplemental tables confirm these concerns and pose the risk of selective citation of (false) positive findings. Researcher degrees of freedom remain high in much of this research as well: There are many outcomes measured, scant protection for multiple comparisons, and concerns about transparency regarding a priori versus post hoc findings and their associated robustness. We are encouraged that research rigor appears to be improving. However, we 
Annual Reviews of Clinical Psychology 16

believe that all these issues combine to require humbler assertions about what we know and do not yet know about the role of stressors and stress allostasis in SUDs. In the remaining sections, we highlight gaps that we observed in the stress-SUD literature; we frame these gaps as opportunities to advance this knowledge as we simultaneously improve our methodical rigor.

\section{Stressors: Characteristics and Context}

It appears that stressor predictability plays an important role in the stressor-drug use relationship. Unpredictable (and uncontrollable) stressors robustly reinstate drug seeking in rodents, whereas the evidence is mixed for other stressors (Mantsch et al. 2016). Koob (2015) implicates neuroadaptations in CRH-sensitive circuits in the central extended amygdala in the etiology of SUDs in rodents. Rodent models suggest that these same CRH circuits are particularly responsive to unpredictable or otherwise uncertain stressors (Davis et al. 2010, Kaye et al. 2017; but see Fox \& Shackman 2019). We documented evidence of maladaptive, exaggerated CNS stress allostasis among individuals with SUDs selectively during unpredictable (but not predictable) stressors. Furthermore, high rates of relapse during early abstinence co-occur with frequent endogenous and exogenous unpredictability-for example, unpredictable onset and intensity of aversive withdrawal symptoms, uncertainty about abstinence efficacy, unexpected exposure to drug cues, opportunities to use, and changes in social networks. Finally, other research demonstrates that acute alcohol administration provides negative reinforcement selectively during unpredictable (but not predictable) stressors (e.g., Bradford et al. 2013, 2017; Hefner et al. 2013).

We propose that systematic research to address clear gaps in our understanding of stressor predictability should be a high priority. For example, studies of stress-induced drug use/relapse or craving have not yet explicitly contrasted unpredictable versus predictable stressors in either animal models or humans. Evidence of maladaptive CNS stress allostasis during unpredictable stressors among humans with SUDs is limited to startle potentiation during shock threat. Research with other stressors and measures of CNS stress allostasis, as well as peripheral allostasis and subjective distress, is needed.

Future research is also needed to clearly define the unpredictability construct and parse it from related constructs. At this point, it appears possible to develop clear, a priori laboratory manipulations of unpredictability in rodents and humans (e.g., see Kaye et al. 2017), but it remains more challenging to prospectively identify and categorize real-world stressors as unpredictable versus predictable. Future in situ research must measure participants' appraisal of stressful events, including their predictability. Furthermore, predictability and controllability are closely related constructs, but stressor controllability has yet to be adequately studied and parsed from predictability in either laboratory or in situ research.

Many other important characteristics of stressors and their contexts have received even less consideration. As noted above (see the section titled Guideposts and Guardrails from Basic Research on 
Stress), functional impairment for most important outcomes (e.g., emotional, behavioral, health) is a nonlinear (inverted U) function of stressor severity/intensity (Sapolsky 2015), but stressor severity is rarely manipulated in the laboratory or measured in the field (but see Moberg et al. 2011). Both basic research and animal models of depression have established controllability as another important stressor characteristic (Maier \& Seligman 2016, Weiss 1972), yet it has also been mostly ignored in stress-SUD research. Sayette (1993) established that stressor appraisal is a key moderator of the stress response-dampening effects of acute alcohol administration, but appraisal processes are not routinely measured when studying stress allostasis or stress-induced drug use in individuals with SUDs. Similarly, contextual factors such as social support and other available coping resources likely matter but remain largely unexamined (Dimoff \& Sayette 2017, Heilig et al. 2016). We strongly call for more routine consideration of these important stressor characteristics and contexts.

\section{Theories and Mechanisms Revisited}

The theoretical models that guided this review differ to some degree regarding the causes and temporal stability of maladaptive stress allostasis. Stress neuroadaptation models propose that chronic drug use negatively affects stress allostasis, whereas other models suggest that maladaptive stress allostasis may be trait-like or at least observed well before any substantial drug use. Crosssectional research with at-risk samples before drug exposure can be combined with research on individuals with active and remitted SUDs to begin to address causal ordering of drug use and maladaptive stress allostasis. However, it is difficult and risky to make inferences about developmental processes by comparing across different cross-sectional samples. Longitudinal research is necessary.

Longitudinal research can also more precisely identify the drug use characteristics most closely associated with changes in stress allostasis if it is indeed not stable over time. Rodent models suggest that particular patterns of drinking [e.g., repeated bingeing and withdrawal (Breese et al. 2005, O'Dell et al. 2004)] or contextual factors such as drug availability (Mantsch et al. 2008) rather than overall quantity may be necessary to promote or express allostatic changes in stress-related neurocircuitry. Consistent with this, Gorka et al. (2016) observed that the frequency of binge drinking in a community sample was positively associated with the magnitude of startle potentiation during unpredictable but not predictable threat. Longitudinal and other research is also necessary to evaluate whether these stress neuroadaptations persist after cessation of drug use. Of course, longitudinal research is time-consuming and costly. However, it may be possible to rely on ongoing national data collection projects such as the Adolescent Brain Cognitive Development (ABCD) Study, the Midlife in the United States (MIDUS) project, and others that collect rich longitudinal data including drug use outcomes.

Koob has focused on two broad classes of neuroadaptations that may contribute to SUD etiology: one within the reward system and a second compensatory, allostatic adaptation where stress 
Annual Reviews of Clinical Psychology 16

system circuitry is strengthened to offset repeated reward system activation (Koob 2015, Koob \& Le Moal 2008). We believe there is sufficient evidence to warrant further investigation of several additional possible allostatic adaptations.

It appears that acute administration of most addictive drugs activates peripheral stress systems (Wemm \& Sinha 2019). The blunted peripheral stress allostasis we observed among individuals with SUDs may result from a compensatory adaptation due to chronic activation by drugs. Similarly, the increased CNS stress allostasis we reported may have resulted from a between-system adaptation whereby increased synaptic plasticity and expansion of dendritic processes in the central extended amygdala were caused by HPA axis glucocorticoid release during this same chronic drug use. Finally, increased CNS stress allostasis in response to unpredictable stressors may also result in part from compensatory adaptation within the CNS due to the stress response-dampening effects of alcohol (and possibly other drugs) during unpredictable stressors (Kaye et al. 2017). We hope these observations of potentially novel stress neuroadaptations encourage multisystemic measurement of stress allostasis both cross-sectionally and longitudinally in humans with SUDs alongside reverse translational research in rodent models.

\section{Individual Differences and the Inverted-U}

Sapolsky (2015) has called attention to the value of considering individual differences framed within the context of the inverted- $U$ of stressor consequences as a function of the stressor's nature, intensity, and duration. This framework allows us to contemplate individual differences in what is considered optimal versus harmful stress with reference to the peak (location and height) and width of this nonlinear function. We can then examine genes, traits, environments, and experiences that promote vulnerability (e.g., a left shift of the U) or resilience to stressors. As noted, there has been little consideration of the natural variation of stressors along continua of intensity, severity, and other characteristics. More problematic, individual difference moderators have been tested and/or reported in a haphazard fashion that makes it difficult to identify robust findings. We believe there is enough evidence and prior research to warrant more consistent examination of sex as a moderator of stress allostasis in SUDs. Sex has been the most frequently considered individual difference moderator in research on stress-induced drug use and stress allostasis in SUDs. More importantly, some evidence suggests that sex differences are possible in both the biological stress systems and the types of stressors experienced as a function of gendered social and cultural roles (Cohen et al. 2019, Hogle \& Curtin 2006, Verplaetse et al. 2015). We did not observe clear patterns of sex moderation of either stress-induced craving/use or stress allostasis in our review, and many studies did not report sex effects. Nonetheless, systematic examination and reporting of sex effects in future research would clarify whether it is indeed an important moderator or whether noted significant findings are spurious.

A handful of other individual differences appear promising to consider in future research on stress mechanisms in SUDs. For example, individual differences in general startle reactivity may 
serve as biomarkers for CNS stress allostasis in the central extended amygdala (Bradford et al. 2014). Increased general startle reactivity predicts greater reactivity to unpredictable stressors and greater negative reinforcement from drinking. Similarly, individual differences in stress-relevant constructs such as anxiety sensitivity, intolerance of uncertainty, and distress tolerance may identify individuals who display deficient or otherwise maladaptive stress coping (Leventhal \& Zvolensky 2015, Zvolensky et al. 2010). Stress-relevant psychiatric and medical conditions like PTSD and chronic pain are promising moderators given their high comorbidities with SUDs (Ditre et al. 2019, Gilpin \& Weiner 2017). Finally, we acknowledge the large body of work that has suggested the importance of chronic and early life stress as moderating variables (see Cohen et al. 2019). Critically, we must use rigorous methods (e.g., preregistration, appropriate corrections for multiple testing, reporting all tested individual differences regardless of outcome) to pursue questions about individual differences if we hope to reach robust conclusions.

\section{Refining in situ Research}

In situ studies have some inherent advantages relative to laboratory research examining stress-induced drug use. In situ stressors are more ecologically valid and varied than what is typically possible in the laboratory. These stressors are also experienced in their natural contexts, which include social support networks and a wider array of available coping strategies and resources that may affect stress allostasis. This context may often include drug cues and/or drugs themselves, again possibly altering key aspects of stress allostasis including behavioral and subjective components. Drug use itself may be more likely in situ than in artificial laboratory settings. Prospective (lagged) analyses of stressor-drug use relationships should be used to enforce the required causal ordering, and different lags (e.g., next hour, next day) can be considered depending on the specific research questions and drug use patterns. However, it is important that future in situ research explicitly identify stressful events rather than simply event-independent negative affect. More detailed measurement of stressor appraisal (stressor characteristics, coping efficacy) should be routinely performed as well. This appears to be the trend among the most recently published studies.

In situ research should also increase the use of alternative measurement beyond self-report. There have been rapid advances in the ability to obtain real-time (or at least time-stamped) information about stressors, their context, and stress allostasis via passive sensing and related approaches including global positioning services (GPS), voice and text message cellular communications, social media activity, and wearable sensors. Natural language processing can identify stressorrelevant content in social media activity (e.g., Facebook posts, comments, direct messages) and text communication via smartphones. GPS and cellular communications can be contextualized by obtaining key characteristics about locations and contact numbers (e.g., unpleasant versus pleasant, associated with past drug use, drugs typically available, health care providers). For example, we can prospectively predict alcohol lapses in newly abstinent individuals with AUD with high accuracy and temporal precision (i.e., identify lapses in the next day with $88 \%$ sensitivity and $70 \%$ specificity) 
using mostly passive measures (Curtin et al. 2015). Clinical research-grade mobile psychophysiology solutions (e.g., Empatica E4 wristband) are now available and are still improving our opportunities to measure real-time peripheral stress allostasis (e.g., electrodermal activity, heart rate, heart rate variability). Transdermal monitoring of real-time alcohol use is rapidly improving and may soon allow passive sensing of alcohol use in clinical research (e.g., BACtrack's SKYN, Milo Sensor's ION). These new and emerging tools and methods will dramatically advance our ability to probe stressordrug use relationships in situ.

Innovative methods are now being used to track and probe in situ stressors as well. For example, Heller and colleagues have developed an event-triggered dense sampling approach for negative and positive affect when undergraduates first view their midterm grades (Villano et al. In press). Equally important, undergraduates also provide a priori reports of their expected grades and other details relevant to understanding their likely appraisal of their grades. Heller is pursuing a similar approach in patients receiving treatment for breast cancer with dense sampling triggered surrounding oncological appointments (LM Baez, MA Antoni, AS Heller, unpublished manuscript). He has also begun to bring these in situ stressors into the laboratory (e.g., undergraduates first receive their real midterm grade in the laboratory during fMRI measurement) (BV Villano, BA Jaso, TR Reneau, C Baldassano, AS Heller, unpublished manuscript). Together these approaches allow for more precise measurement of stressors in situ, and they combine powerful laboratory measurement approaches (fMRI, psychophysiology, hormonal measures) with more naturalistic stressors. Clinical research with SUDs could rely on similar methods to examine stressor-induced craving and stress allostasis in the laboratory with real-world stressors to confirm the generality and ecological validity of stress-SUD relationships.

\section{Advancing Stress-Relevant Treatments}

Despite failures and slow progress to date, there remains an urgent need to develop novel or repurposed medications that target stress mechanisms in SUDs. Several available NE medications (e.g., doxazosin, guanfacine) still hold promise, but further research is needed with larger sample sizes to demonstrate these drugs' efficacy regarding stress-relevant outcomes. Among currently available medications that target CNS stress systems, baclofen, mifepristone, and ketamine warrant further immediate investigation (Butelman \& Kreek 2017, Greenwald 2018). Of course, there remain many other stress-relevant neurotransmitter systems that have potential for future development (e.g., urocortin, dynorphin, neuropeptide Y, hypocretin/orexin) (Greenwald 2018).

We are encouraged that psychosocial treatments (e.g., CBT, MMBIs) that contain components that may affect stress mechanisms do improve drug use outcomes. The most important next step is to evaluate treatment mechanisms explicitly. More generally, increasing the focus on sources of unpredictable stressors and accompanying coping strategies may increase the efficacy of SUD interventions. For example, relapse prevention programs can help patients to better identify risks and 
develop tools to reshape their environments and social interactions to increase predictability and/or seek additional support during high-risk periods.

The use of surrogate end points-early markers of disease process mechanisms with high predictive validity for later clinical outcomes-can increase the pace of clinical trials research to develop, refine, and confirm mechanisms of action for both pharmacological and psychosocial treatments (Kaye et al. 2017). Following from our review, we believe that there are three promising surrogate end points to evaluate treatments that target stress allostasis: the NPU task (Schmitz \& Grillon 2012), the stress imagery task (Sinha 2009), and the Trier social stress task. All three tasks are amenable to measures of subjective emotional response as well as CNS and peripheral stress allostasis to varying degrees.

If properly validated, these surrogate end points may be more sensitive to stress allostasis mechanisms than more distal clinical outcomes (e.g., point-prevalence abstinence, heavy drinking days) that can be influenced by many factors other than stress. As such, they can offer more power and efficiency to screen treatments that target stress-induced relapse. Unfortunately, the predictive validity of the NPU task has not been evaluated to date. Several small-N studies have evaluated the predictive validity of the stress imagery and Trier social stress tasks (Back et al. 2010; Sinha et al. 2006, 2011). However, convincing evidence has not yet accumulated given the inconsistent pattern of associations observed across studies, dependent measures, and clinical outcomes. We believe that validating these surrogate end points in large, well-powered, and ideally preregistered studies should be a top priority to advance development of stress-relevant medications and psychosocial treatments.

Although we have focused on medications and traditional psychosocial treatments, emerging digital technologies have begun to make just-in-time adaptive interventions for SUDs possible (Gustafson et al. 2014). Our observations also reinforce the potential benefits offered by existing but often unavailable or underfunded harm reduction approaches. Individuals with SUDs often experience a disproportionate number of stressors (e.g., financial, legal, housing, medical problems). Many harm reduction approaches can robustly reduce stress and other uncertainty regarding legal, housing, health, and other basic needs (Newman \& Goldman 2008). For example, harm reduction approaches such as Housing First (Davidson et al. 2014), needle exchange programs (Ksobiech 2003), and medication-assisted therapies such as opioid substitution programs (Amato et al. 2005) can substantially reduce these salient stressors while also significantly improving drug use outcomes. Wide-scale implementation of such programs has tremendous potential to reduce or remove stressors by shifting societal attitudes from stigmatization and criminalization toward public health models based on prevention, harm reduction, and treatment. It is an exciting time to study stress, stress allostasis, and SUDs. We eagerly await the next steps. 


\section{SUMMARY POINTS}

1. Stressor characteristics (intensity, unpredictability, uncontrollability) and context (social support, available coping resources/strategies) are important to consider but largely neglected in clinical research on SUDs.

2. Biological systems that mediate stress allostasis are highly interactive, but distinct patterns of stressor allostasis are possible across systems among individuals with SUDs. Clinical research should avoid collapsing measures and systems into a single stress-reactivity construct.

3. Stressors cause craving in the laboratory, but at this point there is insufficient evidence of stressor-induced use in humans.

4. In situ research has only recently begun to explicitly measure stressful events. However, this methodology holds high promise to explore stressor, craving, and drug use relationships.

5. Individuals with SUDs display decreased peripheral stress allostasis, increased central stress allostasis (possibly selective to unpredictable stressors), and unchanged subjective distress compared with healthy controls.

6. Acute drug deprivation does not appear to affect stress allostasis.

7. Effective medications to target stress allostasis in SUDs have not yet been identified. CBT and MMBIs improve SUD clinical outcomes, but their mechanisms have not yet been established.

8. The quality and rigor of clinical research to date examining the stress-SUD relationship warrant much humbler, more cautious conclusions than previous reviews.

\section{FUTURE ISSUES}

1. Although preclinical research has positioned stress as central to many theories of SUD etiology, the stress-SUD field must strive for clear conclusions supported by rigorous human clinical research.

2. Understanding the role of stressor characteristics such as predictability, controllability, severity/intensity, and appraisal/coping should be a high priority given the impetus from basic stress research and preliminary findings in humans with SUDs.

3. Longitudinal research with new and existing data sets can help clarify the mechanisms and developmental processes by which changes in stress allostasis occur. Multisystemic measurement of stress allostasis should become routine.

4. Rigorous and systematic examination of individual differences is needed. This research can be anchored in characteristics of the inverted $U$ to study both vulnerability and resilience.

5. Methodological refinements for in situ research can overcome inherent disadvantages of laboratory research and improve assessment of both stressors and drug use/relapse. 
6. There remain promising pharmacologic targets for stress allostasis in SUDs, but their efficacy in humans must be evaluated with larger sample sizes and stress-relevant surrogate end points alongside clinical outcomes.

7. Effective psychosocial treatments for SUDs should be evaluated explicitly for stress-relevant treatment mechanisms. Surrogate end points, once validated, can assist this effort.

8. Harm reduction should be considered more regularly for SUDs because of its ability to reduce stressor exposure. Just-in-time adaptive interventions are now emerging and also hold high promise.

\section{DISCLOSURE STATEMENT}

JJC is the principal investigator on two active grants from NIH (R01 AA024388 and R01 AA024391). Apart from these, the authors are not aware of any affiliations, memberships, funding, or financial holdings that might be perceived as affecting the objectivity of this review.

\section{LITERATURE CITED}

al'Absi M, Nakajima M, Grabowski J. 2013. Stress response dysregulation and stress-induced analgesia in nicotine dependent men and women. Biol. Psychol. 93(1):1-8.

https://doi.org/10.1016/j.biopsycho.2012.12.007

Amato L, Davoli M, Perucci CA, Ferri M, Faggiano F, Mattick RP. 2005. An overview of systematic reviews of the effectiveness of opiate maintenance therapies: available evidence to inform clinical practice and research. J. Subst. Abuse Treat. 28(4):321-29.

https://doi.org/10.1016/j.jsat.2005.02.007

Armeli S, Dehart T, Tennen H, Todd M, Affleck G. 2007. Daily interpersonal stress and the stressorvulnerability model of alcohol use. J. Soc. Clin. Psychol. 26(8):896-921.

https://doi.org/10.1521/jscp.2007.26.8.896

Arnsten AFT. 2009. Stress signalling pathways that impair prefrontal cortex structure and function. Nat. Rev. Neurosci. 10(6):410-22. https://doi.org/10.1038/nrn2648

Back SE, Hartwell K, DeSantis SM, Saladin M, McRae-Clark AL, et al. 2010. Reactivity to laboratory stress provocation predicts relapse to cocaine. Drug Alcohol Depend. 106(1):21-27. https://doi.org/10.1016/i.drugalcdep.2009.07.016

Baker TB, Piper ME, McCarthy DE, Majeskie MR, Fiore MC. 2004. Addiction motivation reformulated: an affective processing model of negative reinforcement. Psychol. Rev. 111(1):33-51

Binneman B, Feltner D, Kolluri S, Shi Y, Qiu R, Stiger T. 2008. A 6-week randomized, placebo-controlled trial of CP-316,311 (a selective CRH1 antagonist) in the treatment of major depression. Am. J. Psychiatry 165(5):617-20 
Bisaga A, Aharonovich E, Garawi F, Levin FR, Rubin E, et al. 2006. A randomized placebo-controlled trial of gabapentin for cocaine dependence. Drug Alcohol Depend. 81(3):267-74.

https://doi.org/10.1016/j.drugalcdep.2005.07.009

Bowen S, Witkiewitz K, Clifasefi SL, Grow J, Chawla N, et al. 2014. Relative efficacy of mindfulnessbased relapse prevention, standard relapse prevention, and treatment as usual for substance use disorders: a randomized clinical trial. JAMA Psychiatry 71(5):547-56.

https://doi.org/10.1001/jamapsychiatry.2013.4546

Bradford DE, Curtin JJ, Piper ME. 2015. Anticipation of smoking sufficiently dampens stress reactivity in nicotine-deprived smokers. J. Abnorm. Psychol. 124(1):128-36.

https://doi.org/10.1037/abn0000007

Bradford DE, Kaye JT, Curtin JJ. 2014. Not just noise: individual differences in general startle reactivity predict startle response to uncertain and certain threat. Psychophysiology 51(5):407-11. https://doi.org/10.1111/psyp.12193

Bradford DE, Motschman CA, Starr MJ, Curtin JJ. 2017. Alcohol's effects on emotionally motivated attention, defensive reactivity and subjective anxiety during uncertain threats. Soc. Cogn. Affect. Neurosci. 12(11):1823-32

Bradford DE, Shapiro BL, Curtin JJ. 2013. How bad could it be? Alcohol dampens stress responses to threat of uncertain intensity. Psychol. Sci. 24(12):2541-49.

https://doi.org/10.1177/0956797613499923

Breese GR, Overstreet DH, Knapp DJ. 2005. Conceptual framework for the etiology of alcoholism: a "kindling"/stress hypothesis. Psychopharmacology 178:367-80.

https://doi.org/10.1007/s00213-004-2016-2

Brewer JA, Mallik S, Babuscio TA, Nich C, Johnson HE, et al. 2011. Mindfulness training for smoking cessation: results from a randomized controlled trial. Drug Alcohol Depend. 119(1-2):72-80. https://doi.org/10.1016/i.drugalcdep.2011.05.027

Burchfield SR. 1979. The stress response: a new perspective. Psychosom. Med. 41(8):661-72

Butelman ER, Kreek MJ. 2017. Medications for substance use disorders (SUD): emerging approaches. Expert Opin. Emerg. Drugs 22(4):301-15.

https://doi.org/10.1080/14728214.2017.1395855

Button KS, Ioannidis JPA, Mokrysz C, Nosek BA, Flint J, et al. 2013. Power failure: why small sample size undermines the reliability of neuroscience. Nat. Rev. Neurosci. 14(5):365-76. https://doi.org/10.1038/nrn3475

Cannon WB. 1915. Bodily Changes in Pain, Hunger, Fear and Rage: An Account of Recent Researches into the Function of Emotional Excitement. New York: D. Appleton. http://archive.org/details/cu31924022542470

Cannon WB. 1932. The Wisdom of the Body. New York: W.W. Norton

Carroll KM. 1998. A cognitive-behavioral approach: treating cocaine addiction. NIH publ. 98-4308, US Dep. Health Hum. Serv., Natl. Inst. Health, Rockville, MD 
Chattarji S, Tomar A, Suvrathan A, Ghosh S, Rahman MM. 2015. Neighborhood matters: divergent patterns of stress-induced plasticity across the brain. Nat. Neurosci. 18(10):1364-75. https://doi.org/10.1038/nn.4115

Cinciripini PM, Robinson JD, Carter BL, Lam C, Wu X, et al. 2006. The effects of smoking deprivation and nicotine administration on emotional reactivity. Nicotine Tob. Res. 8(3):379-92. https://doi.org/10.1080/14622200600670272

Coffey SF, Saladin ME, Drobes DJ, Brady KT, Dansky BS, Kilpatrick DG. 2002. Trauma and substance cue reactivity in individuals with comorbid posttraumatic stress disorder and cocaine or alcohol dependence. Drug Alcohol Depend. 65(2):115-27. https://doi.org/10.1016/S0376$\underline{8716(01) 00157-0}$

Coffey SF, Schumacher JA, Stasiewicz PR, Henslee AM, Baillie LE, Landy N. 2010. Craving and physiological reactivity to trauma and alcohol cues in posttraumatic stress disorder and alcohol dependence. Exp. Clin. Psychopharmacol. 18(4):340-49. https://doi.org/10.1037/a0019790

Coffey SF, Stasiewicz PR, Hughes PM, Brimo ML. 2006. Trauma-focused imaginal exposure for individuals with comorbid posttraumatic stress disorder and alcohol dependence: revealing mechanisms of alcohol craving in a cue reactivity paradigm. Psychol. Addict. Behav. 20(4):425-35

Cohen S, Murphy MLM, Prather AA. 2019. Ten surprising facts about stressful life events and disease risk. Annu. Rev. Psychol. 70:577-97. https://doi.org/10.1146/annurev-psych-010418102857

Constantinou N, Morgan CJA, Battistella S, O’Ryan D, Davis P, Curran HV. 2010. Attentional bias, inhibitory control and acute stress in current and former opiate addicts. Drug Alcohol Depend. 109(1):220-25. https://doi.org/10.1016/j.drugalcdep.2010.01.012

Cooney NL, Litt MD, Morse PA, Bauer LO, Gaupp L. 1997. Alcohol cue reactivity, negative-mood reactivity, and relapse in treated alcoholic men. J. Abnorm. Psychol. 106(2):243-50. https://doi.org/10.1037/0021-843X.106.2.243

Coric V, Feldman HH, Oren DA, Shekhar A, Pultz J, et al. 2010. Multicenter, randomized, doubleblind, active comparator and placebo-controlled trial of a corticotropin-releasing factor receptor-1 antagonist in generalized anxiety disorder. Depress. Anxiety 27(5):417-25. https://doi.org/10/1002/da.20695

Cronk NJ, Piasecki TM. 2010. Contextual and subjective antecedents of smoking in a college student sample. Nicotine Tob. Res. 12(10):997-1004. https://doi.org/10.1093/ntr/ntq136

Curtin JJ, McCarthy DE, Piper ME, Baker TB. 2006. Implicit and explicit drug motivational processes: a model of boundary conditions. In Handbook of Implicit Cognition and Addiction, ed. RW Wiers, AW Stacy, pp. 233-50. Thousand Oaks, CA: Sage

Curtin JJ, Zhu X, Gustafson D, Alagoz O. 2015. NIAAA R01: dynamic, real-time prediction of alcohol use lapse using mHealth technologies. Open Sci. Framew. (OSF). https://osf.io/szjue/ 
Davidson C, Neighbors C, Hall G, Hogue A, Cho R, et al. 2014. Association of housing first implementation and key outcomes among homeless persons with problematic substance use. Psychiatr. Serv. 65(11):1318-24. https://doi.org/10.1176/appi.ps.201300195

Davis M, Walker DL, Miles L, Grillon C. 2010. Phasic versus sustained fear in rats and humans: role of the extended amygdala in fear versus anxiety. Neuropsychopharmacol. Rev. 35(1):105-35

de Guglielmo G, Cippitelli A, Somaini L, Gerra G, Li H, et al. 2013. Pregabalin reduces cocaine selfadministration and relapse to cocaine seeking in the rat. Addict. Biol. 18(4):644-53.

https://doi.org/10.1111/j.1369-1600.2012.00468.x

de Wit H, Epstein DH, Preston KL. 2018. Does human language limit translatability of clinical and preclinical addiction research? Neuropsychopharmacology 43(10):1985-88.

https://doi.org/10.1038/s41386-018-0095-8

Dimoff JD, Sayette MA. 2017. The case for investigating social context in laboratory studies of smoking. Addiction 112(3):388-95. https://doi.org/10.1111/add.13503

Ditre JW, Zale EL, LaRowe LR. 2019. A reciprocal model of pain and substance use: transdiagnostic considerations, clinical implications, and future directions. Annu. Rev. Clin. Psychol. 15:503-28. https://doi.org/10.1146/annurev-clinpsy-050718-095440

Dunlop BW, Binder EB, Iosifescu D, Mathew SJ, Neylan TC, et al. 2017. Corticotropin-releasing factor receptor 1 antagonism is ineffective for women with posttraumatic stress disorder. Biol. Psychiatry 82(12):866-74. https://doi.org/10.1016/j.biopsych.2017.06.024

Dutra L, Stathopoulou G, Basden SL, Leyro TM, Powers MB, Otto MW. 2008. A meta-analytic review of psychosocial interventions for substance use disorders. Am. J. Psychiatry 165(2):179-87. https://doi.org/10.1176/appi.ajp.2007.06111851

Evans BE, Greaves-Lord K, Euser AS, Tulen JHM, Franken IHA, Huizink AC. 2012. Alcohol and tobacco use and heart rate reactivity to a psychosocial stressor in an adolescent population. Drug Alcohol Depend. 126(3):296-303. https://doi.org/10.1016/j.drugalcdep.2012.05.031

Fox AS, Shackman AJ. 2019. The central extended amygdala in fear and anxiety: closing the gap between mechanistic and neuroimaging research. Neurosci. Lett. 693:58-67.

https://doi.org/10.1016/j.neulet.2017.11.056

Fox HC, Anderson GM, Tuit K, Hansen J, Kimmerling A, et al. 2012a. Prazosin effects on stress- and cue-induced craving and stress response in alcohol-dependent individuals: preliminary findings. Alcohol Clin. Exp. Res. 36(2):351-60. https://doi.org/10.1111/j.1530-0277.2011.01628.x

Fox HC, Hong K-IA, Siedlarz K, Sinha R. 2008. Enhanced sensitivity to stress and drug/alcohol craving in abstinent cocaine-dependent individuals compared to social drinkers. Neuropsychopharmacology 33(4):796-805. https://doi.org/10.1038/sj.npp.1301470

Fox HC, Seo D, Tuit K, Hansen J, Kimmerling A, et al. 2012b. Guanfacine effects on stress, drug craving and prefrontal activation in cocaine dependent individuals: preliminary findings. J. Psychopharmacol. 26(7):958-72. https://doi.org/10.1177/0269881111430746 
Furnari M, Epstein DH, Phillips KA, Jobes ML, Kowalczyk WJ, et al. 2015. Some of the people, some of the time: field evidence for associations and dissociations between stress and drug use. Psychopharmacology 232(19):3529-37. https://doi.org/10.1007/s00213-015-3998-7

Gilpin NW, Weiner JL. 2017. Neurobiology of comorbid post-traumatic stress disorder and alcoholuse disorder. Genes Brain Behav. 16(1):15-43. https://doi.org/10.1111/gbb.12349

Ginty AT, Jones A, Carroll D, Roseboom TJ, Phillips AC, et al. 2014. Neuroendocrine and cardiovascular reactions to acute psychological stress are attenuated in smokers. Psychoneuroendocrinology 48:87-97. https://doi.org/10.1016/j.psyneuen.2014.05.023

Goldberg SB, Tucker RP, Greene PA, Davidson RJ, Wampold BE, et al. 2018. Mindfulness-based interventions for psychiatric disorders: a systematic review and meta-analysis. Clin. Psychol. Rev. 59:52-60. https://doi.org/10.1016/i.cpr.2017.10.011

González G, Desai R, Sofuoglu M, Poling J, Oliveto A, et al. 2007. Clinical efficacy of gabapentin versus tiagabine for reducing cocaine use among cocaine dependent methadone-treated patients. Drug Alcohol Depend. 87(1):1-9. https://doi.org/10.1016/i.drugalcdep.2006.07.003

Gorka SM, Kreutzer KA, Petrey KM, Radoman M, Phan KL. 2019. Behavioral and neural sensitivity to uncertain threat in individuals with alcohol use disorder: associations with drinking behaviors and motives. Addict. Biol. In press. https://doi.org/10.1111/adb.12774

Gorka SM, Lieberman L, Phan KL, Shankman SA. 2016. Association between problematic alcohol use and reactivity to uncertain threat in two independent samples. Drug Alcohol Depend. 164:89-96. https://doi.org/10.1016/i.drugalcdep.2016.04.034

Gorka SM, Shankman SA. 2017. Preliminary evidence that reactivity to uncertain threat is an endophenotype for alcohol use disorder. Drug Alcohol Depend. 180:265-71.

https://doi.org/10.1016/j.drugalcdep.2017.08.023

Greenwald MK. 2018. Anti-stress neuropharmacological mechanisms and targets for addiction treatment: a translational framework. Neurobiol. Stress 9:84-104.

https://doi.org/10.1016/i.ynstr.2018.08.003

Grillon C, Avenevoli S, Daurignac E, Merikangas KR. 2007. Fear-potentiated startle to threat, and prepulse inhibition among young adult nonsmokers, abstinent smokers, and nonabstinent smokers. Biol. Psychiatry 62(10):1155-61. https://doi.org/10.1016/j.biopsych.2006.12.027

Gustafson DH, McTavish FM, Chih M-Y, Atwood AK, Johnson RA, et al. 2014. A smartphone application to support recovery from alcoholism: a randomized clinical trial. JAMA Psychiatry 71(5):566-72. https://doi.org/10.1001/jamapsychiatry.2013.4642

Hart CL, Haney M, Vosburg SK, Rubin E, Foltin RW. 2007. Gabapentin does not reduce smoked cocaine self-administration: employment of a novel self-administration procedure. Behav. Pharmacol. 18(1):71-75. https://doi.org/10.1097/FBP.0b013e328014139d

Heckman BW, Carpenter MJ, Correa JB, Wray JM, Saladin ME, et al. 2015. Effects of experimental negative affect manipulations on ad libitum smoking: a meta-analysis. Addiction 110(5):75160. https://doi.org/10.1111/add.12866 
Annual Reviews of Clinical Psychology 16

Heckman BW, Kovacs MA, Marquinez NS, Meltzer LR, Tsambarlis ME, et al. 2013. Influence of affective manipulations on cigarette craving: a meta-analysis. Addiction 108(12):2068-78. https://doi.org/10.1111/add.12284

Hefner KR, Moberg CA, Hachiya LY, Curtin JJ. 2013. Alcohol stress response dampening during imminent versus distal, uncertain threat. J. Abnorm. Psychol. 122(3):756-69. https://doi.org/10.1037/a0033407

Hefner KR, Starr MJ, Curtin JJ. 2018. Heavy marijuana use but not deprivation is associated with increased stressor reactivity. J. Abnorm. Psychol. 127(4):348-58.

https://doi.org/10.1037/abn0000344

Heilig M, Epstein DH, Nader MA, Shaham Y. 2016. Time to connect: bringing social context into addiction neuroscience. Nat. Rev. Neurosci. 17(9):592-99. https://doi.org/10.1038/nrn.2016.67

Hogle JM, Curtin JJ. 2006. Sex differences in negative affective response during nicotine withdrawal. Psychophysiology 43(4):344-56. https://doi.org/10.1111/j.1469-2006.00406.x

Hogle JM, Kaye JT, Curtin JJ. 2010. Nicotine withdrawal increases threat-induced anxiety but not fear: neuroadaptation in human addiction. Biol. Psychiatry 68(8):687-88.

https://doi.org/10.1016/j.biopsych.2010.06.003

Jansma A, Breteler MH, Schippers GM, de Jong CA, Van Der Staak CF. 2000. No effect of negative mood on the alcohol cue reactivity of in-patient alcoholics. Addict. Behav. 25(4):619-24

Jobes ML, Ghitza UE, Epstein DH, Phillips KA, Heishman SJ, Preston KL. 2011. Clonidine blocks stress-induced craving in cocaine users. Psychopharmacology 218(1):83-88.

https://doi.org/10.1007/s00213-011-2230-7

Kabat-Zinn J. 2005. Full Catastrophe Living: Using the Wisdom of Your Body and Mind to Face Stress, Pain, and Illness. New York: Delta Trade Paperb. 15th anniv. ed.

Kaye JT, Bradford DE, Magruder KP, Curtin JJ. 2017. Probing for neuroadaptations to unpredictable stressors in addiction: translational methods and emerging evidence. J. Stud. Alcohol Drugs 78(3):353-71. https://doi.org/10.15288/jsad.2017.78.353

Kaye JT, Fronk GE, Zgierska AE, Cruz MR, Rabago D, Curtin JJ. 2019. Acute prazosin administration does not reduce stressor reactivity in healthy adults. Psychopharmacology 236:3371-82. https://doi.org/10.1007/s00213-019-05297-x

Kenna GA, Haass-Koffler CL, Zywiak WH, Edwards SM, Brickley MB, et al. 2016. Role of the $\alpha 1$ blocker doxazosin in alcoholism: a proof-of-concept randomized controlled trial. Addict. Biol. 21(4):904-14. https://doi.org/10.1111/adb.12275

Khantzian EJ. 1997. The self-medication hypothesis of substance use disorders: a reconsideration and recent applications. Harv. Rev. Psychiatry 4(5):231-44.

https://doi.org/10.3109/10673229709030550

Kheirabadi GR, Ranjkesh M, Maracy MR, Salehi M. 2008. Effect of add-on gabapentin on opioid withdrawal symptoms in opium-dependent patients. Addiction 103(9):1495-99.

https://doi.org/10.1111/j.1360-0443.2008.02248.x 
Kiluk BD, Carroll KM. 2013. New developments in behavioral treatments for substance use disorders. Curr. Psychiatry Rep. 15(12):420. https://doi.org/10.1007/s11920-013-0420-1

Kober H, Brewer JA, Height KL, Sinha R. 2017. Neural stress reactivity relates to smoking outcomes and differentiates between mindfulness and cognitive-behavioral treatments. Neuroimage 151:4-13. https://doi.org/10.1016/j.neuroimage.2016.09.042

Koob GF. 2015. The dark side of emotion: the addiction perspective. Eur. J. Pharmacol. 753:73-87. https://doi.org/10.1016/j.ejphar.2014.11.044

Koob GF, Le Moal M. 2008. Addiction and the brain antireward system. Annu. Rev. Psychol. 59:2953. https://doi.org/10/1146/annurev.psych.59.103006.093548

Koob GF, Zorrilla EP. 2010. Neurobiological mechanisms of addiction: focus on corticotropin-releasing factor. Curr. Opin. Investig. Drugs 11(1):63-71

Kranzler HR, Feinn R, Morris P, Hartwell EE. 2019. A meta-analysis of the efficacy of gabapentin for treating alcohol use disorder. Addiction. 114(9):1547-55. https://doi.org/10.1111/add.14655

Ksobiech K. 2003. A meta-analysis of needle sharing, lending, and borrowing behaviors of needle exchange program attenders. AIDS Educ. Prev. 15(3):257-68

Kwako LE, Spagnolo PA, Schwandt ML, Thorsell A, George DT, et al. 2015. The corticotropin releasing hormone-1 (CRH1) receptor antagonist pexacerfont in alcohol dependence: a randomized controlled experimental medicine study. Neuropsychopharmacology 40(5):1053-63. https://doi.org/10.1038/npp.2014.306

Lane R, Waldstein S, Chesney M, Jennings J, Lovallo W, et al. 2009. The rebirth of neuroscience in psychosomatic medicine, part I: historical context, methods, and relevant basic science. Psychosom. Med. 71(2):117-34. https://doi.org/10.1097/PSY.0b013e31819783be

Lazarus RS. 1966. Psychological Stress and the Coping Process. New York: McGraw-Hill

Lazarus RS. 1999. Stress and Emotion: A New Synthesis. New York: Springer

Leventhal AM, Zvolensky MJ. 2015. Anxiety, depression, and cigarette smoking: a transdiagnostic vulnerability framework to understanding emotion-smoking comorbidity. Psychol. Bull. 141(1):176-212. https://doi.org/10.1037/bul0000003

Li W, Howard MO, Garland EL, McGovern P, Lazar M. 2017. Mindfulness treatment for substance misuse: a systematic review and meta-analysis. J. Subst. Abuse Treat. 75:62-96. https://doi.org/10.1016/j.jsat.2017.01.008

Magill M, Kiluk BD, McCrady BS, Tonigan JS, Longabaugh R. 2015. Active ingredients of treatment and client mechanisms of change in behavioral treatments for alcohol use disorders: progress 10 years later. Alcohol Clin. Exp. Res. 39(10):1852-62. https://doi.org/10.1111/acer.12848

Magill M, Ray LA. 2009. Cognitive-behavioral treatment with adult alcohol and illicit drug users: a meta-analysis of randomized controlled trials. J. Stud. Alcohol Drugs 70(4):516-27. https://doi.org/10.15288/jsad.2009.70.516

Maier SF, Seligman MEP. 2016. Learned helplessness at fifty: insights from neuroscience. Psychol. Rev. 123(4):349-67. https://doi.org/10.1037/rev0000033 
Mantsch JR, Baker DA, Francis DM, Katz ES, Hoks MA, Serge JP. 2008. Stressor- and corticotropin releasing factor-induced reinstatement and active stress-related behavioral responses are augmented following long-access cocaine self-administration by rats. Psychopharmacology 195(4):591-603. https://doi.org/10.1007/s00213-007-0950-5

Mantsch JR, Baker DA, Funk D, Lê AD, Shaham Y. 2016. Stress-induced reinstatement of drug seeking: 20 years of progress. Neuropsychopharmacology 41(1):335-56. https://doi.org/10.1038/npp.2015.142

Mason BJ, Crean R, Goodell V, Light JM, Quello S, et al. 2012. A proof-of-concept randomized controlled study of gabapentin: effects on cannabis use, withdrawal and executive function deficits in cannabis-dependent adults. Neuropsychopharmacology 37(7):1689-98.

https://doi.org/10.1038/npp.2012.14

Mason BJ, Light JM, Escher T, Drobes DJ. 2008. Effect of positive and negative affective stimuli and beverage cues on measures of craving in non treatment-seeking alcoholics. Psychopharmacology 200(1):141-50. https://doi.org/10.1007/s00213-008-1192-x

Mason BJ, Quello S, Shadan F. 2018. Gabapentin for the treatment of alcohol use disorder. Expert Opin. Investig. Drugs 27(1):113-24. https://doi.org/10.1080/13543784.2018.1417383

Mason JW. 1975. A historical view of the stress field. J. Hum. Stress 1(2):22-36. https://doi.org/10.1080/0097840X.1975.9940405

McCarthy DE, Piasecki TM, Fiore MC, \& Baker TB. 2006. Life before and after quitting smoking: An electronic diary study. Journal of Abnormal Psychology 115(3):454-466. https://doi.org/10.1037/0021-843X.115.3.454

McEwen BS. 2017. Allostasis and the epigenetics of brain and body health over the life course: the brain on stress. JAMA Psychiatry 74(6):551-52. https://doi.org/10.1001/jamapsychiatry.2017.0270

McEwen BS, Gianaros PJ. 2011. Stress- and allostasis-induced brain plasticity. Annu. Rev. Med. 62:431-45. https://doi.org/10.1146/annurev-med-052209-100430

McEwen BS, Wingfield JC. 2010. What's in a name? Integrating homeostasis, allostasis and stress. Horm. Behav. 57(2):105-111. https://doi.org/10.1016/i.yhbeh.2009.09.011

McKee SA, Potenza MN, Kober H, Sofuoglu M, Arnsten AFT, et al. 2015. A translational investigation targeting stress-reactivity and prefrontal cognitive control with guanfacine for smoking cessation. J. Psychopharmacol. 29(3):300-11. https://doi.org/10.1177/0269881114562091

Moberg CA, Bradford DE, Kaye JT, Curtin JJ. 2017. Increased startle potentiation to unpredictable stressors in alcohol dependence: possible stress neuroadaptation in humans. J. Abnorm. Psychol. 126(4):441-53. https://doi.org/10.1037/abn0000265

Moberg CA, Weber S, Curtin JJ. 2011. Alcohol dose effects on stress response to cued threat vary by threat intensity. Psychopharmacology 218:217-27 
Moran LM, Kowalczyk WJ, Phillips KA, Vahabzadeh M, Lin J-L, et al. 2018. Sex differences in daily life stress and craving in opioid-dependent patients. Am. J. Drug Alcohol Abuse 44(5):512-23. https://doi.org/10.1080/00952990.2018.1454934

Myrick H, Henderson S, Malcolm R. 2001. Gabapentin in the treatment of cocaine dependence: a case series. J. Clin. Psychiatry 62(1):19-23

Nakajima M, Al'Absi M. 2014. Nicotine withdrawal and stress-induced changes in pain sensitivity: a cross-sectional investigation between abstinent smokers and nonsmokers. Psychophysiology 51(10):1015-22. https://doi.org/10.1111/psyp.12241

Neupert SD, Desmarais SL, Gray JS, Cohn AM, Doherty S, Knight K. 2017. Daily stressors as antecedents, correlates, and consequences of alcohol and drug use and cravings in community-based offenders. Psychol. Addict. Behav. 31(3):315-25. https://doi.org/10.1037/adb0000276

Newman S, Goldman H. 2008. Putting housing first, making housing last: housing policy for persons with severe mental illness. Am. J. Psychiatry 165(10):1242-48.

https://doi.org/10.1176/appi.ajp.2008.08020279

O’Dell LE, Roberts AJ, Smith RT, Koob GF. 2004. Enhanced alcohol self-administration after intermittent versus continuous alcohol vapor exposure. Alcohol. Clin. Exp. Res. 28(11):1676-82. https://doi.org/10.1097/01.ALC.0000145781.11923.4E

Peckham AM, Evoy KE, Ochs L, Covvey JR. 2018. Gabapentin for off-label use: evidence-based or cause for concern? Subst. Abuse 12. https://doi.org/10.1177/1178221818801311

Petrakis IL, Desai N, Gueorguieva R, Arias A, O’Brien E, et al. 2016. Prazosin for veterans with posttraumatic stress disorder and comorbid alcohol dependence: a clinical trial. Alcohol Clin. Exp. Res. 40(1):178-86. https://doi.org/10.1111/acer.12926

Phillips AC, Der G, Hunt K, Carroll D. 2009. Haemodynamic reactions to acute psychological stress and smoking status in a large community sample. Int. J. Psychophysiol. 73(3):273-78. https://doi.org/10.1016/j.ijpsycho.2009.04.005

Piper ME, Curtin JJ. 2006. Tobacco withdrawal and negative affect: an analysis of initial emotional response intensity and voluntary emotion regulation. J. Abnorm. Psychol. 115(1):96-102. http://dx.doi.org.ezproxy.library.wisc.edu/10.1037/0021-843X.115.1.96

Pratt WM, Davidson D. 2009. Role of the HPA axis and the A118G polymorphism of the mu-opioid receptor in stress-induced drinking behavior. Alcohol Alcohol. 44(4):358-65.

https://doi.org/10.1093/alcalc/agp007

Preston KL, Kowalczyk WJ, Phillips KA, Jobes ML, Vahabzadeh M, et al. 2017. Context and craving during stressful events in the daily lives of drug-dependent patients. Psychopharmacology 234(17):2631-42. https://doi.org/10.1007/s00213-017-4663-0

Preston KL, Kowalczyk WJ, Phillips KA, Jobes ML, Vahabzadeh M, et al. 2018a. Before and after: craving, mood, and background stress in the hours surrounding drug use and stressful events in patients with opioid-use disorder. Psychopharmacology 235(9):2713-23.

https://doi.org/10.1007/s00213-018-4966-9 
Annual Reviews of Clinical Psychology 16

Preston KL, Schroeder JR, Kowalczyk WJ, Phillips KA, Jobes ML, et al. 2018b. End-of-day reports of daily hassles and stress in men and women with opioid-use disorder: relationship to momentary reports of opioid and cocaine use and stress. Drug Alcohol Depend. 193:21-28. https://doi.org/10.1016/i.drugalcdep.2018.08.023

Raby WN, Coomaraswamy S. 2004. Gabapentin reduces cocaine use among addicts from a community clinic sample. J. Clin. Psychiatry 65(1):84-86

Ray LA. 2011. Stress-induced and cue-induced craving for alcohol in heavy drinkers: preliminary evidence of genetic moderation by the OPRM1 and CRH-BP genes. Alcohol Clin. Exp. Res. 35(1):166-74. https://doi.org/10.1111/i.1530-0277.2010.01333.x

Roberto M, Gilpin NW, O'Dell LE, Cruz MT, Morse AC, et al. 2008. Cellular and behavioral interactions of gabapentin with alcohol dependence. J. Neurosci. 28(22):5762-71. https://doi.org/10.1523/INEUROSCI.0575-08.2008

Salehi M, Kheirabadi GR, Maracy MR, Ranjkesh M. 2011. Importance of gabapentin dose in treatment of opioid withdrawal. J. Clin. Psychopharmacol. 31(5):593-96. https://doi.org/10.1097//CP.0b013e31822bb378

Sapolsky RM. 2015. Stress and the brain: individual variability and the inverted-U. Nat. Neurosci. 18(10):1344-46. https://doi.org/10.1038/nn.4109

Sayette MA. 1993. An appraisal-disruption model of alcohol's effects on stress responses in social drinkers. Psychol. Bull. 114(3):459-76

Schmitz A, Grillon C. 2012. Assessing fear and anxiety in humans using the threat of predictable and unpredictable aversive events (the NPU-threat test). Nat. Protoc. 7(3):527-32. https://doi.org/10.1038/nprot.2012.001

Schwandt ML, Cortes CR, Kwako LE, George DT, Momenan R, et al. 2016. The CRF1 antagonist verucerfont in anxious alcohol-dependent women: translation of neuroendocrine, but not of anti-craving effects. Neuropsychopharmacology 41:2818-29.

https://doi.org/10.1038/npp.2016.61

Segal ZV, Williams JMG, Teasdale JD, Kabat-Zinn J. 2012. Mindfulness-Based Cognitive Therapy for Depression. New York: Guilford. 2nd ed.

Segerstrom SC, Miller GE. 2004. Psychological stress and the human immune system: a meta-analytic study of 30 years of inquiry. Psychol. Bull. 130(4):601-30. https://doi.org/10.1037/00332909.130.4.601

Selye H. 1936. A syndrome produced by diverse nocuous agents. Nature 138:32. https://doi.org/10.1038/138032a0

Selye H. 1975. Confusion and controversy in the stress field. J. Hum. Stress 1(2):37-44

Serre F, Fatseas M, Denis C, Swendsen J, Auriacombe M. 2018. Predictors of craving and substance use among patients with alcohol, tobacco, cannabis or opiate addictions: commonalities and specificities across substances. Addict. Behav. 83:123-29.

https://doi.org/10.1016/j.addbeh.2018.01.041 
Shaham Y, de Wit H. 2016. Lost in translation: CRF1 receptor antagonists and addiction treatment. Neuropsychopharmacology 41(12):2795-97. https://doi.org/10.1038/npp.2016.94

Sheffield D, Smith GD, Carroll D, Shipley MJ, Marmot MG. 1997. The effects of recent food, alcohol, and tobacco intake and the temporal scheduling of testing on cardiovascular activity at rest and during psychological stress. Psychophysiology 34(2):204-12. https://doi.org/10.1111/j.14698986.1997.tb02133.x

Sher KJ. 1987. Stress response dampening. In Psychological Theories of Drinking and Alcoholism, ed. HT Blane, KE Leonard, pp. 227-71. New York: Guilford

Shiffman S, Waters AJ. 2004. Negative affect and smoking lapses: a prospective analysis. J. Consult. Clin. Psychol. 72(2):192-201. https://doi.org/10.1037/0022-006X.72.2.192

Simpson TL, Saxon A, Meredith C, Malte C, McBride B, et al. 2009. A pilot trial of the alpha-1 adrenergic antagonist, prazosin, for alcohol dependence. Alcohol. Clin. Exp. Res. 33(2):255-63.

https://doi.org/10.1111/j.1530-0277.2008.00807.x

Simpson TL, Saxon AJ, Stappenbeck C, Malte CA, Lyons R, et al. 2018. Double-blind randomized clinical trial of prazosin for alcohol use disorder. Am. J. Psychiatry 175(12):1216-24.

https://doi.org/10.1176/appi.ajp.2018.17080913

Sinha R. 2009. Modeling stress and drug craving in the laboratory: implications for addiction treatment development. Addict. Biol. 14(1):84-98. https://doi.org/10.1111/j.13691600.2008.00134.x

Sinha R, Fox HC, Hong KA, Bergquist K, Bhagwagar Z, Siedlarz KM. 2009. Enhanced negative emotion and alcohol craving, and altered physiological responses following stress and cue exposure in alcohol dependent individuals. Neuropsychopharmacology 34(5):1198-208.

https://doi.org/10.1038/npp.2008.78

Sinha R, Fox HC, Hong K-IA, Hansen J, Tuit K, Kreek MJ. 2011. Effects of adrenal sensitivity, stressand cue-induced craving, and anxiety on subsequent alcohol relapse and treatment outcomes. Arch. Gen. Psychiatry 68(9):942-52. https://doi.org/10.1001/archgenpsychiatry.2011.49

Sinha R, Garcia M, Paliwal P, Kreek MJ, Rounsaville BJ. 2006. Stress-induced cocaine craving and hypothalamic-pituitary-adrenal responses are predictive of cocaine relapse outcomes. Arch. Gen. Psychiatry 63(3):324-31. https://doi.org/10.1001/archpsyc.63.3.324

Sinha R, Kimmerling A, Doebrick C, Kosten T. 2007. Effects of lofexidine on stress-induced and cueinduced opioid craving and opioid abstinence rates: preliminary findings. Psychopharmacology 190(4):569-74. https://doi.org/10.1007/s00213-006-0640-8

Sinha R, Talih M, Malison R, Cooney N, Anderson GM, Kreek MJ. 2003. Hypothalamic-pituitary-adrenal axis and sympatho-adreno-medullary responses during stress-induced and drug cue-induced cocaine craving states. Psychopharmacology 170(1):62-72.

https://doi.org/10.1007/s00213-003-1525-8 
Smith R, Aston-Jones G. 2008. Noradrenergic transmission in the extended amygdala: role in increased drug-seeking and relapse during protracted drug abstinence. Brain Struct. Funct. 213(1-2):43-61. https://doi.org/10.1007/s00429-008-0191-3

Stopponi S, Somaini L, Cippitelli A, de Guglielmo G, Kallupi M, et al. 2012. Pregabalin reduces alcohol drinking and relapse to alcohol seeking in the rat. Psychopharmacology 220(1):87-96. https://doi.org/10.1007/s00213-011-2457-3

Tackett JL, Brandes CM, King KM, Markon KE. 2019. Psychology's replication crisis and clinical psychological science. Annu. Rev. Clin. Psychol. 15:579-604. https://doi.org/10.1146/annurevclinpsy-050718-095710

Tang Y-Y, Tang R, Posner MI. 2016. Mindfulness meditation improves emotion regulation and reduces drug abuse. Drug Alcohol Depend. 163(Suppl. 1):S13-18. https://doi.org/10.1016/j.drugalcdep.2015.11.041

Tapper K. 2018. Mindfulness and craving: effects and mechanisms. Clin. Psychol. Rev. 59:101-17. https://doi.org/10.1016/j.cpr.2017.11.003

Vanderkaay MM, Patterson SM. 2006. Nicotine and acute stress: effects of nicotine versus nicotine withdrawal on stress-induced hemoconcentration and cardiovascular reactivity. Biol. Psychol. 71(2):191-201. https://doi.org/10.1016/j.biopsycho.2005.04.006

Verplaetse TL, Weinberger AH, Oberleitner LM, Smith KM, Pittman BP, et al. 2017. Effect of doxazosin on stress reactivity and the ability to resist smoking. J. Psychopharmacol. 31(7):830-40. https://doi.org/10.1177/0269881117699603

Verplaetse TL, Weinberger AH, Smith PH, Cosgrove KP, Mineur YS, et al. 2015. Targeting the noradrenergic system for gender-sensitive medication development for tobacco dependence. Nicotine Tob. Res. 17(4):486-95. https://doi.org/10.1093/ntr/ntu280

Villano WJ, Ezie CEC, Gillis R, Otto AR, Heller AS. In press. Temporal dynamics of real-world emotion are more strongly linked to prediction error than outcome. J. Exp. Psychol. Gen.

Volz AR, Dennis PA, Dennis MF, Calhoun PS, Wilson SM, Beckham JC. 2014. The role of daily hassles and distress tolerance in predicting cigarette craving during a quit attempt. Nicotine Tob. Res. 16(6):872-75. https://doi.org/10.1093/ntr/ntt286

Ward MM, Swan GE, Jack LM, Javitz HS. 1994. Effect of smoking cessation and relapse on cardiovascular levels and reactivity. Psychopharmacology 114(1):147-54

Weiss JM. 1972. Psychological factors in stress and disease. Scientific American 226(6):104-13

Wemm SE, Sinha R. 2019. Drug-induced stress responses and addiction risk and relapse. Neurobiol. Stress 10:100148. https://doi.org/10.1016/j.ynstr.2019.100148

Wielgosz J, Goldberg SB, Kral TRA, Dunne JD, Davidson RJ. 2019. Mindfulness meditation and psychopathology. Annu. Rev. Clin. Psychol. 15:285-316. https://doi.org/10.1146/annurev-clinpsy$\underline{021815-093423}$

Witkiewitz K, Bowen S, Harrop EN, Douglas H, Enkema M, Sedgwick C. 2014. Mindfulness-based treatment to prevent addictive behavior relapse: theoretical models and hypothesized 
mechanisms of change. Subst. Use Misuse 49(5):513-24.

https://doi.org/10.3109/10826084.2014.891845

Witkiewitz K, Lustyk MKB, Bowen S. 2013. Retraining the addicted brain: a review of hypothesized neurobiological mechanisms of mindfulness-based relapse prevention. Psychol. Addict. Behav. 27(2):351-65. https://doi.org/10.1037/a0029258

Zvolensky MJ, Vujanovic AA, Bernstein A, Leyro T. 2010. Distress tolerance. Curr. Dir. Psychol. Sci. 19(6):406-10. https://doi.org/10.1177/0963721410388642

Zvolensky MJ, Yartz AR, Gregor K, Gonzalez A, Bernstein A, et al. 2008. Interoceptive exposurebased cessation intervention for smokers high in anxiety sensitivity: a case series. J. Cogn. Psychother. 22(4):346-65. https://doi.org/10.1891/0889-8391.22.4.346 